DIW BERLIN

Discussion Papers

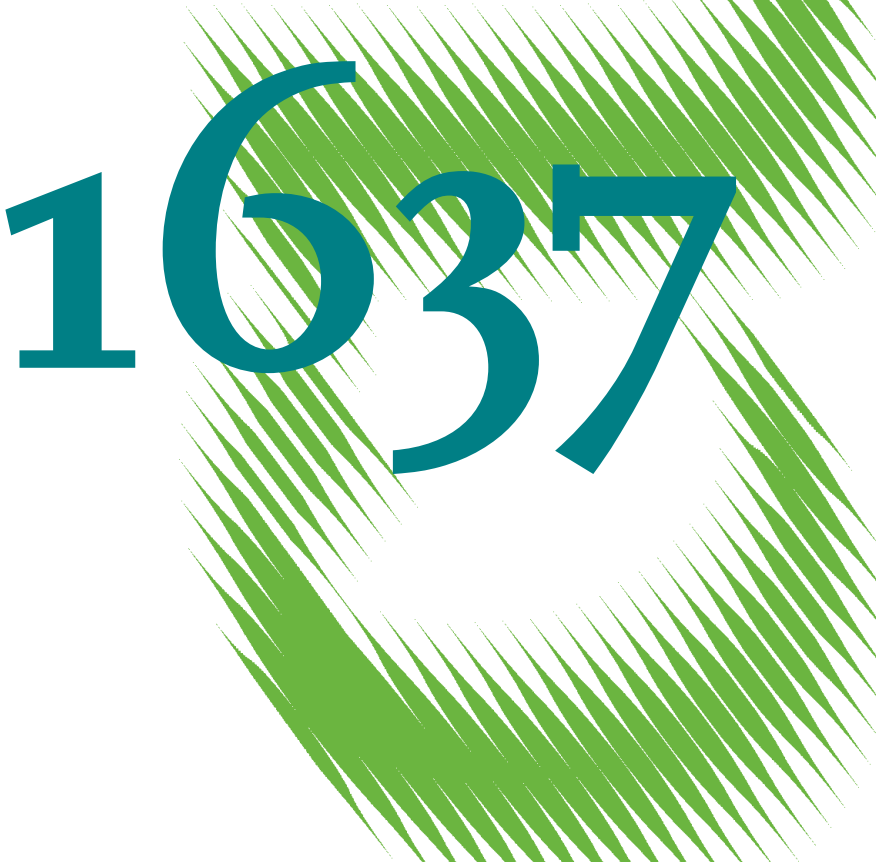

Prosumage of Solar Electricity:

Pros, Cons, and the System

Perspective 
Opinions expressed in this paper are those of the author(s) and do not necessarily reflect views of the institute.

IMPRESSUM

(C) DIW Berlin, 2017

DIW Berlin

German Institute for Economic Research

Mohrenstr. 58

10117 Berlin

Tel. +49 (30) $89789-0$

Fax +49 (30) $89789-200$

http://www.diw.de

ISSN electronic edition 1619-4535

Papers can be downloaded free of charge from the DIW Berlin website:

http://www.diw.de/discussionpapers

Discussion Papers of DIW Berlin are indexed in RePEc and SSRN:

http://ideas.repec.org/s/diw/diwwpp.html

http://www.ssrn.com/link/DIW-Berlin-German-Inst-Econ-Res.html 


\title{
Prosumage of solar electricity: pros, cons, and the system perspective
}

\author{
Wolf-Peter Schill ${ }^{1}$, Alexander Zerrahn, Friedrich Kunz \\ All DIW Berlin, Department of Energy, Transportation, Environment \\ Mohrenstraße 58, 10117 Berlin, Germany
}

January 2017

\begin{abstract}
We examine the role of prosumage of solar electricity, i.e. PV self-generation combined with distributed storage, in the context of the low-carbon energy transformation. First, we devise a qualitative account of arguments in favor of and against prosumage. Second, we give an overview of prosumage in Germany. Prosumage will likely gain momentum as support payments expire for an increasing share of PV capacities after 2020. Third, we model possible system effects in a German 2035 scenario. Prosumage batteries allow for a notable substitution of other storage facilities only if fully available for market interactions. System-friendly operation would also help limiting cost increases. We conclude that policymakers should not unnecessarily restrict prosumage, but consider system and distributional aspects.
\end{abstract}

Keywords: Prosumage, battery storage, PV, energy transformation, DIETER.

JEL: C61, Q42, Q48

Acknowledgements: We thank Eric Borden, Weert Canzler, Jochen Diekmann, Christian von Hirschhausen, Claudia Kemfert, Karsten Neuhoff, Michael Pahle and the participants of the DIW Berlin Sustainability Cluster Seminar for valuable comments; the usual disclaimer applies. A shorter version of this article appears in Economics of Energy \& Environmental Policy, https://doi.org/10.5547/2160-5890.6.1.wsch.

\footnotetext{
${ }^{1}$ Corresponding author. wschill@diw.de, +49 303 89789-675.
} 


\section{Introduction}

Spurred by technology development and regulatory frameworks, self-consumption of distributed renewable electricity generation has gained relevance in many power markets around the world. ${ }^{2}$ Building on the concept of "prosumers" (producers and consumers) or "prosumption" ${ }^{3}$, the term "prosumage" has emerged. Prosumage additionally includes energy storage that can be used to increase self-consumption (producers, consumers and storage) ${ }^{4}$

This paper deals with the role of prosumage in the context of the low-carbon energy transformation. Its purpose is threefold: first, we discuss arguments in favor of and against increasing prosumage. Second, we give a brief overview of prosumage developments in Germany; this also addresses an international readership because Germany can be considered an international frontrunner in this respect. ${ }^{5}$ Third, we present a quantitative model analysis to illustrate possible system effects of increased prosumage.

While the literature on electricity self-consumption is relatively broad and includes a range of different technologies and applications, we largely focus on small-scale photovoltaics (PV) combined with stationary battery storage in grid-connected private households. We do not consider other energy storage technologies that may also play a role in the medium term, including grid-connected electric vehicles, small-scale hydrogen storage systems, and heat storage. Likewise, the focus of our analysis is somewhat narrower compared to the ongoing European policy debate on self-consumption, which also deals with other generation technologies, demand-side management (DSM), and energy efficiency measures not only in the residential, but also in the commercial and industrial sectors, and which not necessarily includes battery storage (cf. European Commission 2015, 2016). Yet we touch upon a range of more general aspects of the self-consumption debate at several instances.

To be precise, we define prosumage as follows: prosumagers are grid-connected electricity consumers who own small-scale PV generators as well as batteries, and use these installations to produce their own electricity at times, draw electricity from the grid at other times, and feed electricity to the grid at yet other times. Further, we explicitly include potential additional grid interactions of prosumagers' batteries as opposed to, for example, Green and Staffell (forthcoming).

\footnotetext{
${ }^{2}$ Compare also Green and Staffell (forthcoming), Pérez-Arriaga and Jenkins (forthcoming), and MacGill and Smith (forthcoming).

${ }^{3}$ The term "prosumer" dates back to Toffler (1980). This "study of tomorrow" hypothesizes a societal shift toward fragmented, multilateral economic interactions driven by information flows and new technologies. ${ }^{4}$ The growing importance of renewable self-consumption is also reflected in the proposal for a revised European renewable directive, where a respective new article 21 is introduced (European Commission 2016). ${ }^{5}$ See Section 3. MacGill and Smith (forthcoming) provide a comparable assessment with a particular focus on the Australian National Electricity Market.
} 
We connect to different streams of the literature, touching upon different aspects of power system decentralization, distributed generation, self-consumption, and socio-economic issues of the energy transformation. A range of studies analyzes prosumage exclusively from a consumer perspective without considering power system implications. In an early engineering study, which draws on experiments in a prototype prosumage system with storage and demand-side management, CastilloCagigal et al. (2011) find that oversized storage hardly increases self-consumption. They also illustrate that DSM gets more important in case of low storage capacity, and vice versa.

Luthander et al. (2015) provide a detailed review of model-based analyses on increased PV selfconsumption by means of storage and DSM. They find that self-consumption can be increased by around $13-24 \%$ by means of $0.5-1.0 \mathrm{kWh}$ storage per kW of installed PV capacity. Hoppmann et al. (2014), who also review papers dealing with the economics of prosumage from a consumer perspective, analyze the economics of residential prosumage in Germany and find that storage systems for small-scale PV systems get viable first. Larger system sizes become profitable with higher electricity retail prices and lower wholesale prices.

Quoilin et al. (2016) simulate PV self-consumption for different households in various EU countries and find that self-consumption rates without batteries vary between $30 \%$ and $37 \%$. This rate increases with PV and battery sizes, but full autarky would require excessive oversizing of both the PV system and the battery. ${ }^{6}$ Moreover, the profitability of prosumage heavily depends on indirect subsidies provided by the regulatory environment.

For the US, a Rocky Mountain Institute study argues that PV and batteries together may trigger mass "grid defection" of customers in the longer run (RMI 2014). In five US regions, grid parity of solar-plusbattery systems could be reached well below the 30-year-economic lifetime of central energy infrastructure, with stranded assets as a consequence. Because of specific conditions, grid defection would be profitable particularly early for commercial users in New York and California (by 2025 and 2031, respectively). In a follow-up study, the focus is on the more likely case of "load defection" in the sense that solar-plus-battery systems would be still connected to the grid. Such systems would become economical much sooner in the investigated US cases (RMI 2015).

Further literature deals with potential system and societal effects of prosumage. Römer et al. (2012) present an interview-based study on positive externalities of decentralized storage, and other smart grid infrastructure, which may impede socially optimal deployment.

Eid et al. (2014) demonstrate that net metering schemes, which are present in several US markets, lead to inequality problems. Such net metering schemes, which net grid feed-in and grid consumption

\footnotetext{
${ }^{6}$ Green and Staffell (forthcoming) come to a similar conclusion.
} 
over a specified period and, thus, work with a single meter, were introduced in California (Borenstein 2015) and several EU countries (European Commission 2015). Picciariello et al. (2015) quantify crosssubsidies from prosumagers to consumers for twelve stylized US networks and find that these may become substantial, particularly in lower-density grids.

Parag and Sovacool (2016) discuss potential market design issues of prosumage and propose strategies for integrating prosumagers into competitive electricity markets. Pérez-Arriaga and Jenkins (forthcoming) provide an in-depth analysis of the regulatory framework and derive recommendations for efficient future power systems with different kinds of electricity users.

In an IEA (2014) report, several drivers for prosumage growth are discussed. These include economic drivers such as decreasing system costs as well as high electricity retail prices, behavioral drivers such as environmental awareness or (perceived) energy autonomy, and technological drivers like storage technology breakthroughs. Moreover, there are specific national conditions such as roof space availability, the tenant-ownership structure, and the design of distribution grids. A "prosumage revolution" has certainly not arrived by the mid-2010s (IEA 2014). PV self-consumption without storage is more profitable than prosumage in most countries, and applications, today (see also SPE 2016). In Prognos (2016), it is argued that PV energy storage systems may, from a consumer perspective, continue to be economically inferior to PV systems without storage even in case of decreasing storage costs because PV costs over-proportionally decrease further. Bardt et al. (2014) further show that the economic potential of self-consumption strongly depends on the regulatory framework. In a stylized simulation for Germany, the potential for residential self-consumption is very high in case of continued implicit support, but vanishes in case of changed regulation.

The remainder of this paper is structured as follows: Section 2 presents and briefly discusses the most important arguments for and against increased prosumage. Section 3 gives an overview of prosumage incentives and developments in Germany. Section 4 presents a numerical analysis of potential system effects of increased prosumage. The final Section 5 concludes.

\section{A discussion of pros and cons}

In the following, we discuss arguments in favor of and against increasing prosumage in the context of the low-carbon energy transformation. An overview is presented in Table 1. When looking at potential benefits of prosumage, the point of reference is a more centrally operated system with the same renewable generation capacity-and not an alternative fossil-based system. Some pros and cons may be valid only from particular perspectives, for example, from an individual prosumager, a system operator, a utility or society at large. Related collections of pros and cons can be found in IEA (2014), CEER (2016), and NREL (2013). 
Arguments in favor of prosumage

- Consumer preferences

- Participation and acceptance of energy transformation

- $\quad$ Lower and less volatile electricity costs

- Activation of private capital

- $\quad$ Flexibility, sector coupling, and energy efficiency

- Distribution grid relief

- Transmission grid relief

- Increased competition

- Local benefits

- Political economy and new institutional arguments
Arguments against prosumage

- Efficiency losses

- Distributional impacts

- Rebound effects

- Concerns about data protection and remote control

Table 1: Overview of potential pros and cons

\subsection{Arguments in favor of increased prosumage}

\section{Consumer preferences}

Consumers may have preferences for local renewable energy solutions, for being independent from the energy industry, and for energy autarky, even if the latter is only perceived or only partially realized (cf. IEA 2014, Prognos 2016). This point has also been prominently mentioned by consumers who had invested in PV-connected batteries in Germany. ${ }^{7}$ While such preferences may undoubtedly exist, empirical evidence is scarce: two studies for Germany identify preferences for self-generation and independence from energy suppliers as most important drivers for the adoption of generation-plusstorage installations (Gährs et al. 2015, Oberst and Madlener 2015). However, more research is needed to assess external validity and the situation in other countries.

\section{Participation and acceptance of the energy transformation}

Another important argument in favor of prosumage relates to higher public acceptance of the energy transformation, and the actual realization of respective energy policy targets. A motivation for consumers to become prosumagers is a preference to actively participate in the low-carbon energy transformation (Gährs et al. 2015). ${ }^{8}$ Moreover, prosumage solutions could mitigate conflicts around infrastructure that is perceived to be related to a more "central" grid design, for example, large-scale renewable generators, transmission infrastructure, and pumped hydro storage (cf. SPE 2015, 2016). Likewise, prosumage incentives could help to fully realize the rooftop PV potential of a specific country or region. While prosumage is, thus, likely to improve the acceptance of the low-carbon energy

\footnotetext{
${ }^{7}$ See RWTH (2016). Wissenschaftliches Mess- und Evaluierungsprogramm Solarstromspeicher. Jahresbericht 2016. ISEA, RWTH Aachen.

${ }^{8}$ See also RWTH (2016), op cit.
} 
transformation for such customers who actively engage in prosumage, the effect on other customers is not clear. This may also depend on overall cost effects and distributional aspects (cf. Section 2.2).

\section{Lower and less volatile electricity costs}

Another argument-and a selling point of prosumage system providers-is that PV in combination with battery storage allows electricity consumers to realize lower and less volatile electricity costs as compared to grid-based power consumption (SPE 2015, cf. also Hoppmann et al. 2014, and RMI 2015). It should be noted that this argument focuses on a consumer perspective. It may depend on direct and indirect regulatory support of prosumage, and may not necessarily correspond to an overall system perspective.

\section{Activation of private capital}

Prosumage may help to mobilize "cheap" private capital for PV and storage investments (EPIA 2013, SPE 2015). While in the current 2017 low-interest environment, capital shortage may not be considered a bottleneck of the energy transformation, this may become more important in the future once interest rates increase again. Arguing from a system perspective, capital should only flow into such investments that are most beneficial in the power system. As regards power storage in Germany, there are doubts if additional storage is required at all in the near future, depending on assumptions made on other flexibility options. ${ }^{9}$

\section{Flexibility, sector coupling, and energy efficiency}

Prosumage could also trigger additional system flexibility, for example by unlocking previously untapped residential demand-side management potentials (cf. Anda and Temmen, 2014). ${ }^{10}$ Likewise, it may catalyze sector coupling. For example, prosumagers could also charge their electric vehicles with self-generated electricity, or attach decentral power-to-heat applications to their batteries (Prognos 2016, SPE 2016). In Germany, such sector coupling is assumed to be required to achieve energy and climate policy targets. ${ }^{11}$ Realizing such additional flexibility potentials requires appropriate regulation (CEER 2016). In particular, it has been argued that prosumagers should be exposed to market prices, and net-metering should be avoided (cf. next section).

Further, prosumage may contribute to improving energy efficiency because of increased awareness of owners and respective behavioral change. Luthander et al. (2015) briefly review studies on households'

\footnotetext{
${ }^{9}$ For short-, mid-, and long-term storage requirements in Germany, see Egerer and Schill (2014) and Schill and Zerrahn (forthcoming). For a European perspective compare Pape et al. (2014), who argue that even in the long run there may not be much need for additional power storage.

${ }^{10}$ Keirstead (2007) provides an early qualitative study on the effects of self-generation on domestic energy consumption in the UK, yet without including batteries.

${ }^{11}$ See BMWi (2016a). Impulspapier Strom 2030: Langfristige Trends - Aufgaben für die kommenden Jahre. German Federal Ministry for Economic Affairs and Energy. Berlin, September 2016.
} 
behavioral responses to PV installations. Several studies indicate that there may be, at least stated, adjustments with respect to load management or energy conservation. The same may also apply to prosumage. Not least, prosumage systems could also contribute to the provision of a range of ancillary services provision in case of proper regulatory setting.

\section{Distribution grid relief}

Increased prosumage may allow to defer distribution grid investments and reduce grid losses. This can be achieved by lower peak PV feed-in levels, which are a major determinant for grid dimensioning. As illustrated in the right panel of Figure 1, system-oriented battery charging can reduce maximum feedin compared to other charging strategies (left panel). What is more, gradients of PV feed-in can also be reduced. Yet such system-oriented battery operation requires respective incentives, regulatory conditions, or centrally controlled battery charging. The latter, in turn, would require appropriate communication infrastructure and the willingness of owners to allow third parties access to their systems. Weniger et al. (2015) discuss different strategies for decentral load and PV forecasts which would help realizing such charging strategies without remote control, and argue for establishing a dynamic instead of a static feed-in reduction based on daily forecasts. Moshövel et al. (2015) also illustrate how prosumagers' batteries could reduce peak PV feed-in by using a simple forecast strategy.
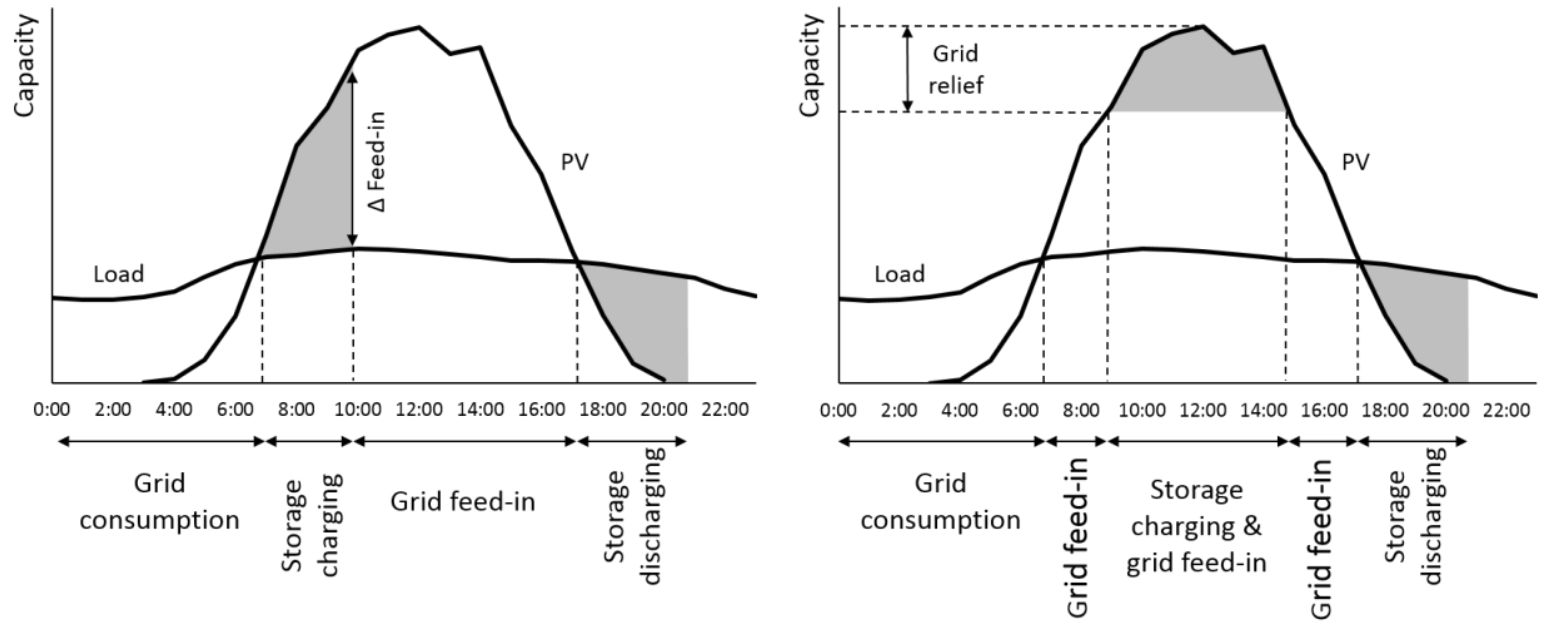

Figure 1: Stylized illustration of load, PV generation, and storage operation under myopic (left panel) and system-oriented (right panel) charging. System-oriented battery charging can reduce maximum distribution grid feed-in and mitigate feed-in gradients. Source: own depiction

Such grid-relieving prosumage benefits would be conceivable if the alternative approach of distribution grid extension was more expensive or more difficult to implement than decentralized storage expansion. This may heavily depend on the grid structure. From a grid-relieving perspective, prosumage is particularly favorable where peak demand and generation are highly correlated, and 
where grid extension is difficult (CEER 2016). As for distribution grid losses, it has been found that, in general, low penetration levels of distributed generation reduce losses, but the opposite can be true for high penetration in case of reverse flows (Tractebel and Ecofys 2015).

\section{Transmission grid relief}

Prosumage may also help to defer transmission grid investments (Deutsch and Graichen 2015, NREL 2013). Yet the mechanisms are not straightforward. The transmission network differs from the distribution network because it is designed for a spatial balancing of energy sources and sinks. As this spatial distribution differs in time, electricity flows in the transmission network vary in level and direction. The effects of prosumage on the transmission network depend, amongst other factors, on the distribution of load and renewable generation. If prosumage smoothes PV peak feed-in in distribution grids, this can also lead to lower transmission network usage and losses. Accordingly, transmission investments that are driven by the integration of renewable generation could potentially be lowered through prosumage.

In contrast, the effect on transmission investments that are mainly driven by peak load depends on the correlation of renewable feed-in and peak load. If they show a rather good match, for instance peak load in summer with high PV feed-in, a decreasing effect of prosumage on transmission investment needs could be expected. However, if peak load and renewable generation do not match (for instance peak load in winter with low PV availability), prosumage may hardly lower network investment needs.

Further, if prosumage batteries are used not only for taking up decentral PV generation, but also for electricity from the grid, adverse transmission network impacts may occur. Prosumagers could be incentivized to store grid energy in situations with low market prices even if residential PV generation is low. Depending on the characteristics of the system, the energy stored by prosumagers could then have to be transported through the transmission network and, consequently, may increase network utilization. In any case, a materialization of the potential benefits of prosumage with respect to distribution and transmission grid developments requires a proper accounting for prosumage in network expansion planning and system operation (CEER 2016).

\section{Increased competition}

Other arguments in favor of prosumage include the assertion of increased competition in electricity markets through new players (SPE 2015, 2016). While this primarily relates to the emergence of new service providers and aggregators, increasing prosumage also reduces the size of the traditional retail market. 


\section{Local benefits}

Further, it is argued that prosumage may incur greater local economic benefits compared to systems owned and operated by other agents (IEA 2014). Yet the overall economic effect when decreasing grid charges, taxes, and other retail price constituents are considered is not clear and subject to complementary research.

\section{Political economy and new institutional arguments}

Finally, a range of arguments draws on political economy and new institutional economics. A growing prosumage segment may allow to further expand PV without relying on direct support schemes, which are politically often subject to controversy and, thus, risky from a project developer perspective (cf. EPIA 2013). Further, prosumage may result in lower rent-seeking activities of well-organized incumbent energy industry lobby groups such as network operators or large utilities. Prosumage could also help to politically address the issue of temporary renewable surplus curtailment. Not least, increased prosumage may spur innovation with respect to hard- and software development as well as new business models. ${ }^{12}$

Many of these arguments rest on the implicit assumption of bounded rationality of individuals, or an assumption that alternative "central" solutions would involve frictions. Some actors also seem to perceive decentral generation and storage solutions as socially preferable solutions per se (cf. Römer et al. 2012). Accordingly, proponents of increased prosumage tend to recommend respective supportive measures, or at least not to put barriers to the further development of the prosumage sector (SPE 2016). In particular, they claim that self-consumed electricity should not be exposed to taxes, grid fees, and other surcharges in order to realize the potential benefits of prosumage discussed above (EPIA 2013, SPE 2015, 2016).

\subsection{Arguments against prosumage}

\section{Efficiency losses}

Compared to a frictionless, centrally optimized power system with the same renewable capacity as point of reference, prosumage incurs additional system costs, which can be interpreted as efficiency losses. This is because greater levels of prosumage imply increased local balancing of renewable and load variability, and less wide-area balancing. Large-scale geographical balancing generally allows to exploit complementary time profiles of load and renewables as well as complementary generation and

\footnotetext{
${ }^{12}$ Ohlhorst (2015) argues that innovation in low-carbon technologies may also be spurred by appropriate multilevel governance arrangements. While she focuses on support for renewable generation in the German federal Bund-Länder setting, a similar argument could be made for prosumage.
} 
flexibility portfolios at different locations. ${ }^{13}$ With decentralized PV batteries, such benefits cannot be realized to their full extent (even if the batteries were operated in a system-friendly way). As a result, excessive and redundant storage capacity and other infrastructures for renewable integration may be required. ${ }^{14}$ As compared to large-scale central storage options, small-scale decentralized batteries also tend to have higher specific costs. Further, prosumage could trigger sub-optimal siting and dimensioning of individual PV systems. The size of prosumage-oriented PV systems tends to be small (Borenstein 2015), and potentially too small compared to what would be optimal from a system perspective (cf. European Commission 2015).

Aside from such portfolio effects, storage attached to decentral PV installations may also be operated in a sub-optimal way. If prosumagers do not consider market prices while operating their batteries, these are not put to the best possible use from a system perspective with respect to net load smoothing (Green and Staffell forthcoming). Without system-oriented charging, prosumage can also lead to steeper gradients of PV feed-in (left panel of Figure 1), which in turn may require costly shortterm system flexibility measures. The Council of European Energy Regulators (CEER 2016) accordingly argues that renewable self-generation tariffs should reflect the full system costs of energy exchanged with the grid, and that regulation should generally adhere to market and efficiency principles.

\section{Distributional impacts}

A substantial part of the potential distributional impacts of prosumage is related to its interaction with grid charges (see Picciariello et al. 2015, and Bardt et al. 2014 for the specific situation in Germany). Grid charges, which reflect the network's fixed and variable costs, are largely energy-based (volumetric) in most electricity markets. As fixed grid costs must be spread over ever fewer customers in case of increasing prosumage, a self-enforcing "utility death spiral" could materialize (cf. Mayr et al. 2015, NREL 2013, Parag and Sovacool 2016). Because of early adopters, this could seriously erode utilities' business models even before mass grid defection (RMI 2014). At the same time, continued energy-based grid charging would unfairly burden consumers that cannot turn into prosumagers. Given that prosumage is most likely implemented by consumers belonging to the upper segments of the income distribution-because prosumagers ideally own a roof, i.e., a house-it may entail a potential regressive effect (cf. Bardt et al. 2014, Borenstein 2015). A comparable argument applies to

\footnotetext{
${ }^{13}$ For European illustrations of the system cost advantages of geographic balancing, see Haller et al. (2012) or Fürsch et al. (2013); for a corresponding US example, see MacDonald et al. (2015).

${ }^{14}$ We illustrate this effect for excess power storage installations in our model-based analysis presented in Section 4. A similar reasoning may apply to the provision of security of supply. For example, Neuhoff et al. (2016) argue that it would be beneficial to share and coordinate the provision of capacity reserves between different countries.
} 
other volumetric constituents of the retail price, such as energy taxes and other surcharges, if these do not apply to self-consumed electricity.

Accordingly, CEER demands to avoid cross-subsidies between prosumers and other consumers (CEER 2016). ${ }^{15} \mathrm{~A}$ US perspective on adequate rate design for increasing shares of prosumage is provided in NREL (2013). A common finding in the literature is that net metering approaches are deemed particularly challenging in case of growing prosumage penetration, as the time value of electricity is not considered, and grid backup is not properly valued under this scheme (cf. Eid et al. 2014). As pure volumetric charges for grid electricity can become problematic in case of increased prosumage, several forms of capacity-based charges and hybrid solutions have been proposed (NREL 2013, European Commission 2015, Pérez-Arriaga and Jenkins forthcoming). ${ }^{16}$

Putting the distributional challenges into perspective, net effects may actually be rather low if offsetting factors are accounted for, such as lower renewable support payments caused by prosumage PV. ${ }^{17}$ Likewise, a study on the particular German setting argues that distributive effects of prosumage are likely to remain limited because the actual potential for PV self-consumption in Germany is fairly low (Prognos 2016).

\section{Rebound effects}

On the upside, prosumage could incentivize energy conservation because of increasing awareness of the installation owners (see Section 2.1). Yet the opposite effect could materialize as well if prosumagers realized lower electricity costs compared to the retail price. With cheap self-generated electricity, prosumagers may have less incentives to realize costly energy saving potentials, or could be tempted to excessively use electricity for power-to-heat and other sector coupling applications. Then, again, small-scale prosumage systems, on average, should not generate any excess electricity, such that self-generated electricity would actually not be cheap at the margin, and a rebound effect should not occur. Empirical evidence on this aspect is largely missing so far. ${ }^{18}$

\section{Policy coordination and path dependency}

A market-driven uptake of prosumage could turn out to be challenging with respect to energy policy coordination. For instance, meeting a given renewable energy expansion target may be easier to

\footnotetext{
${ }^{15}$ Different charging models are sketched out in European Commission (2015). For an overview of proposals specifically dealing with the allocation of network fees, see May and Neuhoff (2016).

${ }^{16}$ Ultimately, even such schemes may not be able to sustain network financing in the long run, as load defection could merely be delayed up to the point of "grid defection" where consumers massively go off-grid, irrespective of the charging scheme (RMI 2015).

${ }^{17}$ See RWTH (2016), op cit.

18 The empirical analysis presented by Motlagh et al. (2015) may be interpreted as a first step in this direction.
} 
achieve with "central" support schemes oriented at grid feed-in as compared to potentially uncontrolled prosumage expansion.

Further, different path dependency effects could materialize. With respect to technological path dependency, battery set-ups could be designed such that system-oriented operations of prosumage installations are unlikely to occur, e.g. if communication interfaces are missing or default operation modes neglect system needs. Likewise, political path dependency may turn residential and commercial prosumage interest groups into a political force. According to IEA (2014), massive deployment of smallscale residential PV systems has already created a new class of "solar voters" in many countries. With mass adoption of decentralized batteries, these may well evolve to become "prosumager voters".

\section{Concerns about privacy and data protection}

When prosumagers provide their flexibility to the energy system, some form of communication interface and remote control is likely to be necessary. Consumers may be concerned about insufficient data protection and loss of control over their batteries, which may hamper the offtake of prosumage. However, empirical evidence on individual preferences is scarce - and mixed. One study from Israel, a technology-positive society as such, points toward significant concerns about data protection and low acceptance of remote control (Michaels and Parag 2016). A slightly more positive finding emerges in a descriptive study for Germany (Gährs et al. 2015).

\section{Prosumage in Germany}

In this section, we give an overview of prosumage incentives in Germany. Driven by indirect and direct support measures, incentives for prosumage can be considered higher than in most other countries (cf. IEA 2014). ${ }^{19}$ To put prosumage into perspective, we also provide some descriptive data on PV and battery installations.

\subsection{Indirect support of prosumage}

As in most other European countries (cf. European Commission 2015), grid fees and other parts of retail prices, including surcharges for renewable energy support, are paid volumetrically in Germany, that is on a per kWh basis. Volumetric pricing generally tends to incentivize prosumage (IEA 2014). Yet a restructuring of grid tariffs is being discussed, which may eventually result in a shift toward more capacity-based pricing schemes.

The feed-in tariff (FIT) for small-scale PV installations has been decreasing strongly through 2016, triggered by falling levelized costs of electricity (LCOE). By 2016, the FIT was much lower than the retail

\footnotetext{
${ }^{19}$ PV-related prosumage is not the only and certainly not the most relevant self-consumption sector in Germany today. Bardt et al. (2014) show that industry, the commercial sector, and transportation historically had (and still have) much larger shares in overall self-consumption, largely based on CHP generation, than households engaging in PV prosumage.
} 
price (right panel of Figure 2). Accordingly, it was more profitable to substitute grid consumption, which has an average retail price of approximately 0.29 Euro/kWh, with self-consumed electricity (difference " $A$ " between retail price and levelized costs of PV) than feeding this electricity to the grid under the feed-in tariff of around 0.12 Euro $/ \mathrm{kWh}^{20}$ (difference "B" between FIT and LCOE, assuming that LCOE are actually lower than the FIT). Accordingly, there is room for prosumagers to increase selfconsumption even if this involves additional (storage) costs. It should be noted that volumetric charging of retail price constituents such as the EEG (the German Renewable Energy Sources Act) surcharge, grid fees, and taxes contributes considerably to this setting in which the levelized costs of PV are cheaper than after-tax retail prices, which can be referred to as "socket parity" (cf. IEA 2014). Back in 2009, the situation was different: retail prices were lower and feed-in tariffs much higher (left panel) such that the difference " $A$ " between the retail price and levelized costs of PV was negative. Accordingly, this setting provided no incentives for self-consumption.

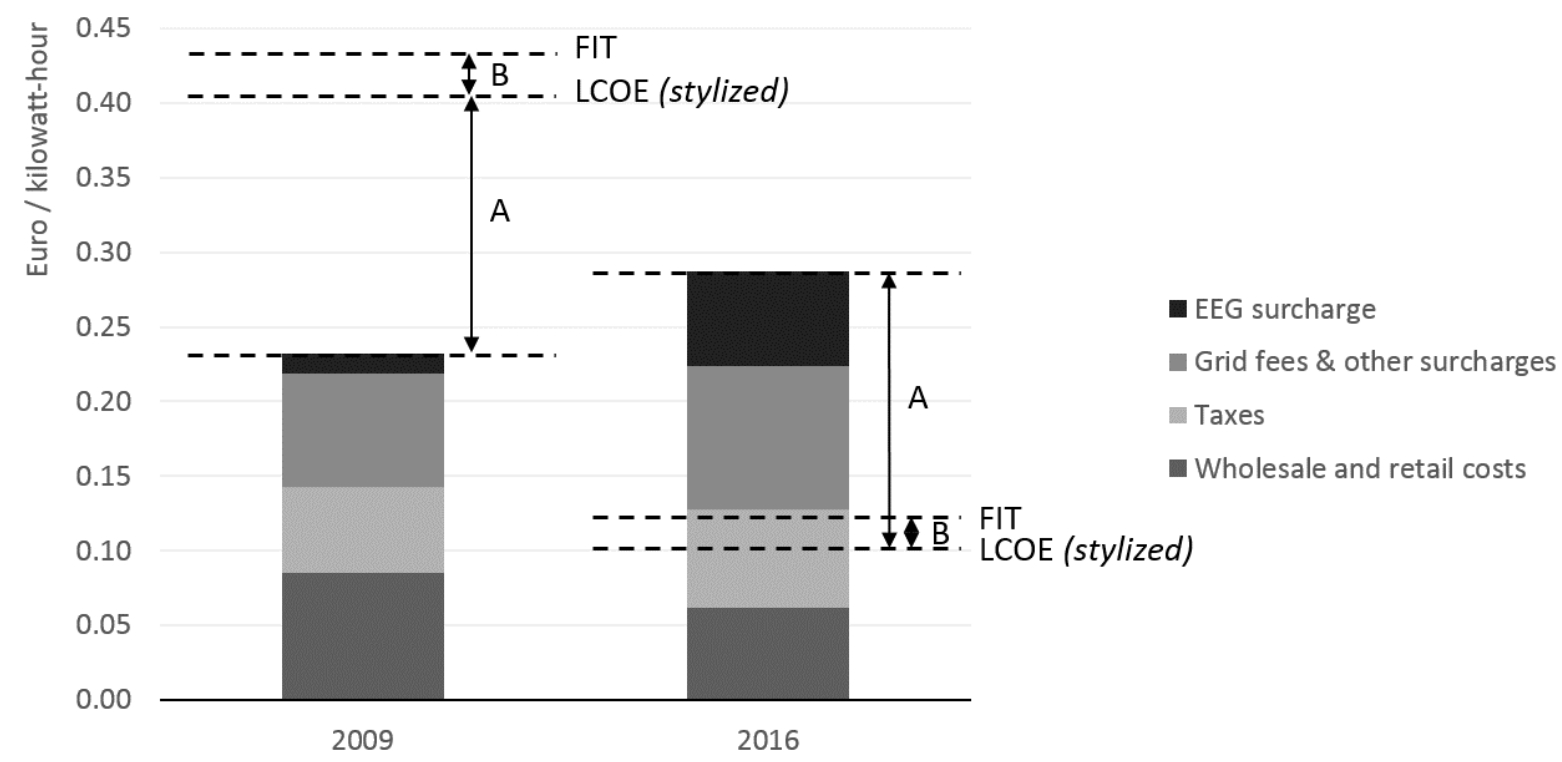

Figure 2: Retail prices for residential consumers (based on BDEW 2016) 21, feed-in tariffs for small-scale PV, and PV LCOE (stylized) in Germany in 2009 and 2016. By 2016, the FIT has fallen way below retail prices, thus providing an incentive for self-consumption

The 2014 EEG reform introduced a change that counteracts prosumage incentives by demanding that PV installations larger than $10 \mathrm{~kW}$, and with self-consumption levels of more than $10 \mathrm{MWh}$ per year, must pay $30 \%$ of the EEG surcharge that is also paid by other non-privileged electricity consumers. This share increased to 40\% with the new EEG 2017.

\footnotetext{
${ }^{20}$ We refer to the 2016 level of the fixed feed-in tariff of small-scale PV installations $<10 \mathrm{~kW}$.

${ }^{21}$ BDEW (2016): BDEW-Strompreisanalyse Mai 2016: Haushalte und Industrie. Berlin, 24. May 2016.
} 


\subsection{Direct support of prosumage}

Aside from indirect support as discussed above, there are also direct incentives for prosumage in Germany. The EEG 2009 introduced a dedicated premium for self-consumed electricity, which was intended to mitigate the difference between retail prices and LCOE (illustrated as " $A$ " in the left panel of Figure 2). This premium initially amounted to 0.25 Euro/kWh in 2009 and decreased in subsequent years. By 2012, it was abolished because of increasing retail prices and decreasing LCOE of PV. ${ }^{22}$

In 2013, another specific support measure for prosumage was introduced with the so-called "KfW program 275" that subsidizes the installation of battery storage connected to small-scale PV systems. In its first phase between 2013 and 2015, the program was funded with 25 million Euro. After an evaluation, and guided by academic recommendations, a second phase of the program started in March 2016 and will run until the end of $2018 .^{23}$

Importantly, the $\mathrm{KfW}$ scheme includes provisions that are intended to incentivize system-oriented storage design and operation - which was one of the motivations for implementing the support scheme in the first place. ${ }^{24}$ First, maximum grid feed-in of the PV system must be reduced to $50 \%$ of the installed PV peak power. This provision, which is valid over the whole lifetime of the PV system, results in a (static) feed-in cap that is intended to induce grid-relieving feed-in, similar to the one shown in the right panel of Figure 1. Second, communication interface requirements are specified which should enable bi-directional ancillary service provision of prosumagers' storage devices. These provisions are aligned with the program's objectives of targeting the market and technology development of battery system as well as better grid integration of PV systems. To this end, a "critical mass" of supported storage systems would be required. To put this notion into perspective, such effects may alternatively be triggered by other regulatory measures. In any case, the KfW program is intensively monitored and, thus, constantly generates - as other supportive policies - new empirical data researchers can draw on.

\subsection{Deployment in Germany}

By January 2016, around 34,000 PV prosumage systems were installed in Germany according to a storage monitoring report, with a cumulative capacity of $200 \mathrm{MWh}{ }^{25}$ Around $55 \%$ have been

\footnotetext{
${ }^{22}$ For similar self-consumption incentives in Italy, see Chiaroni et al. (2014).

${ }^{23}$ The program is funded with 10 million Euro per year: it includes a subsidized loan from the state-owned KfW bank, and an additional investment grant for PV systems smaller than $30 \mathrm{~kW}$ installed since 2013. The loan amounts to 2,000 Euro/kW PV for newly installed systems, and 2,200 Euro/kW for upgrades of existing systems. A part of this loan does not have to be paid back (investment grant). The size of this grant initially amounted to $25 \%$ of the loan in early 2016 , and this value decreases to $10 \%$ by the end of 2018 . See $\mathrm{KfW}$ (2016). Merkblatt Erneuerbare Energien KfW-Programm Erneuerbare Energien "Speicher". Frankfurt, August 2016.

${ }^{24}$ See RWTH (2015). Nachhaltige Entwicklung dezentraler Solarstromspeicher aus wissenschaftlicher Sicht. Ergebnisse der Begleitforschung. ISEA, RWTH Aaachen.

${ }^{25}$ RWTH (2016) op cit.
} 
supported by the KfW scheme mentioned above. Drawing on more recent data sources, it can be inferred that an additional 14,000 PV-connected batteries were installed in Germany by the end of 2016 , summing up to about 48,000 systems. ${ }^{26}$ In 2015 , nearly every second small-scale PV system was installed together with a battery. Starting from a very low level in 2013, the prosumage segment has grown quickly. Because of decreasing costs, the dominant type of installations has recently shifted from lead-acid to lithium-ion batteries.

Future growth rates of the PV prosumage segment in Germany are uncertain and strongly depend on the evolution of the regulatory environment (cf. Bardt et al. 2014). A recent study (Prognos 2016) concludes that the overall electricity generation potential for prosumage in single- and two-family houses, in the agricultural sector, and in food retail buildings is rather modest, with $44 \mathrm{TWh}$ achievable by the year 2035; about half of this represents additional power-to-heat applications.

PV capacity by size in GW

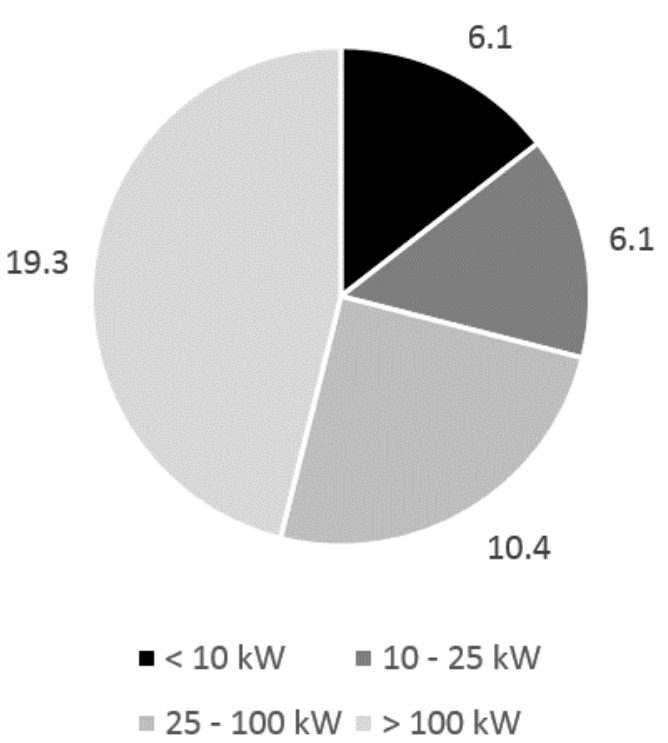

Number of PV installations in millions

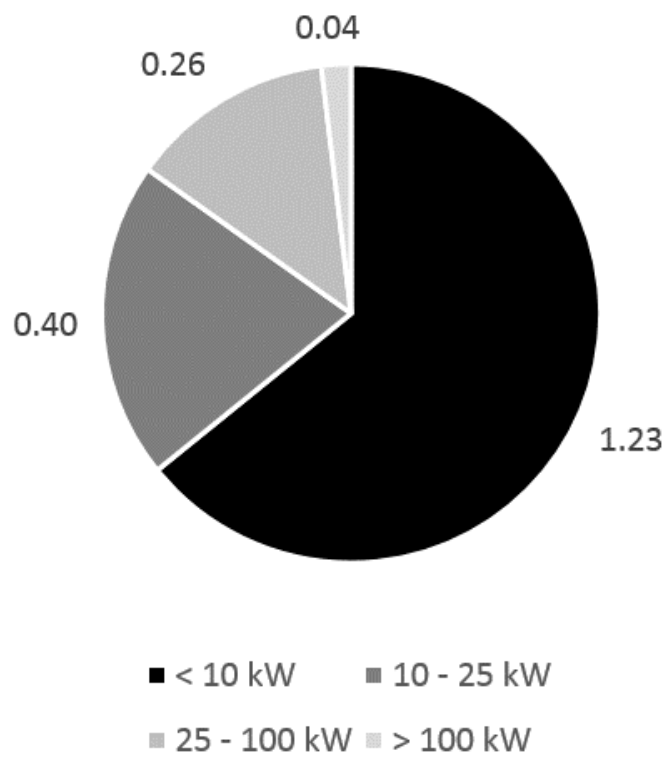

Figure 3: German PV installations as of June 2016. By mid-2016, most PV installations were small-scale; however, largerscale installations provided the bulk of capacity. Source: own calculations based on Open Power System Data, http://openpower-system-data.org, Data Package Renewable power plants, version 2016-10-21

The uptake of prosumage is to be understood in the context of overall PV development in Germany. In the 2010s, Germany has experienced a massive PV deployment. By mid-2016, the overall installed

\footnotetext{
${ }^{26}$ According to a KfW report, 6,263 new storage systems were supported between 01.01.2016 and 30.09.2016. Assuming an equal distribution over respective months and continued deployment in the following months, this corresponds to 696 systems per month, or 7,655 systems in eleven months. With a share of $55 \%$ of supported batteries, we derive an overall deployment of 13,918 systems since February 2016.
} 
capacity was nearly $42 \mathrm{GW}$, with around $6 \mathrm{GW}$ in the small-scale segment below $10 \mathrm{~kW}$, which is often considered particularly suitable for prosumage. ${ }^{27}$ Another $6 \mathrm{GW}$ are in the segment of installations up to $25 \mathrm{~kW}$. The relevance of such small-scale systems is even larger with respect to the number of installations, with more than 1.2 million systems smaller than $10 \mathrm{~kW}$ installed.

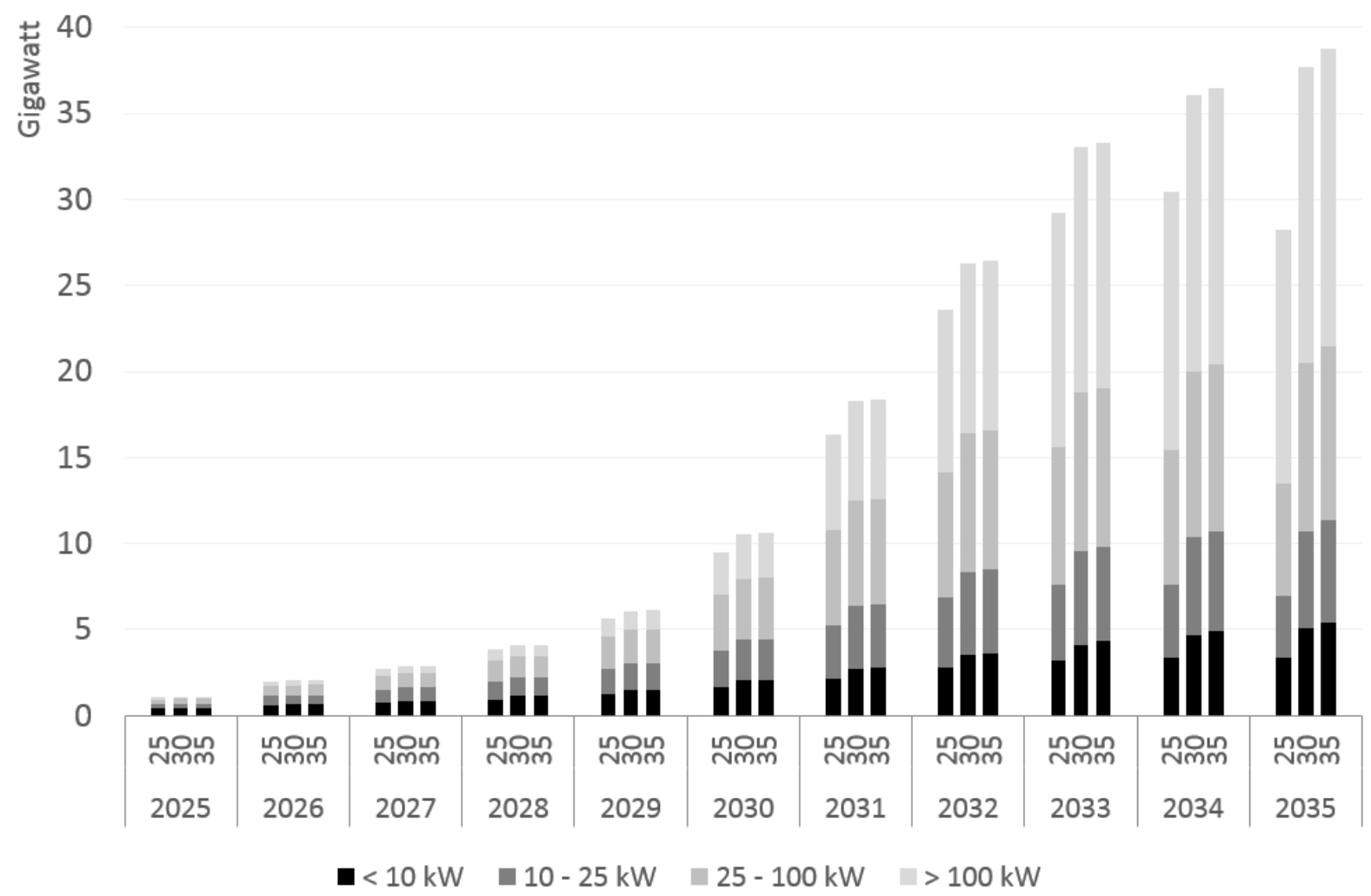

Figure 4: German PV capacity outside the EEG support scheme. Beginning from the mid-2020s, large PV capacities will drop out of the subsidy scheme if their technical lifetime is longer than 20 years. Source: own illustration based on Open Power System Data, http://open-power-system-data.org, Data Package Renewable power plants, version 2016-10-21

By 2016, the largest part of the German PV capacity was installed under the different versions of the EEG since 2000. While feed-in tariffs for newly installed plants were modified many times, the overall remuneration period was largely held constant with 20 years counting from the year of deployment. Yet the technical lifetime of a PV installation may well exceed this 20 years. ${ }^{28} \mathrm{It}$ is conceivable that a substantial fraction of the plants dropping out of the EEG after 20 years will be upgraded with storage devices and, thus, turn into prosumage systems. Figure 4 illustrates the cumulative capacity outside

\footnotetext{
${ }^{27}$ Open Power System Data, http://open-power-system-data.org, Data Package Renewable power plants, version 2016-10-21.

${ }^{28}$ The power rating of a PV installation is likely to decline somewhat with increasing age, which we abstract from in the following. Likewise, inverter lifetimes are generally smaller than module lifetimes, such that inverters may have to be replaced more than once in the lifetime of a module. Nonetheless, lifetimes of 35 years and beyond for PV modules are considered plausible.
} 
the EEG support scheme for different size groups and lifetime assumptions of 25, 30, and 35 years. Between 2020 and 2024, around 1 GW of PV drops out of the support scheme, reflecting the installations in the years 2000 through 2004. Yet by the mid-2020s, this number grows substantially, also for smaller installations, and the cumulative capacity exceeds $30 \mathrm{GW}$ - of which about $20 \mathrm{GW}$ are sized below $100 \mathrm{~kW}$ and, thus, potentially suitable for prosumage - by the early 2030s. Accordingly, policymakers who seek to shape the prosumage sector should use the coming years to prepare for this development.

\section{A model-based illustration of system-wide efficiency losses}

To quantitatively illustrate selected electricity system effects of prosumage, we employ an extended version of the open source electricity system model DIETER for stylized 2035 scenarios for Germany. The model's objective is to minimize overall system costs, consisting of investment and operational costs, over one year in hourly resolution. Input data is based on projections for Germany concerning both future costs and availabilities of technologies, and employs inelastic hourly demand and feed-in factors of variable renewables in Germany. For transparency and replicability, DIETER is open-source: code and data for this and previous versions are available online under open-source licenses. ${ }^{29}$ The basic model is described in Zerrahn and Schill (forthcoming). Applications with respect to long-term requirements of (central) storage and grid interactions of electric vehicles are documented in Schill and Zerrahn (forthcoming) and Schill et al. (2016).

\subsection{An augmented model version}

We augment DIETER by a novel representation of a prosumage segment that complements the wholesale market representation of the general model. ${ }^{30}$ To this end, a specified share of overall solar PV capacities is attributed to prosumage, and load is split into a prosumager and a market share as well. Figure 5 illustrates the prosumage setup: in each hour, energy generated by prosumage PV is either consumed directly, sent to the market, curtailed, or enters the prosumager storage. An hourly prosumage energy balance ensures that prosumager demand is satisfied, by direct self-consumption, consumption of energy from the market or discharging from prosumager storage.

\footnotetext{
${ }^{29}$ See www.diw.de/dieter for the model and previous publications. A complete description of all model equations and input data is also available on the website.

${ }^{30}$ The (existing) wholesale part of the model is referred to as "market" in the following.
} 


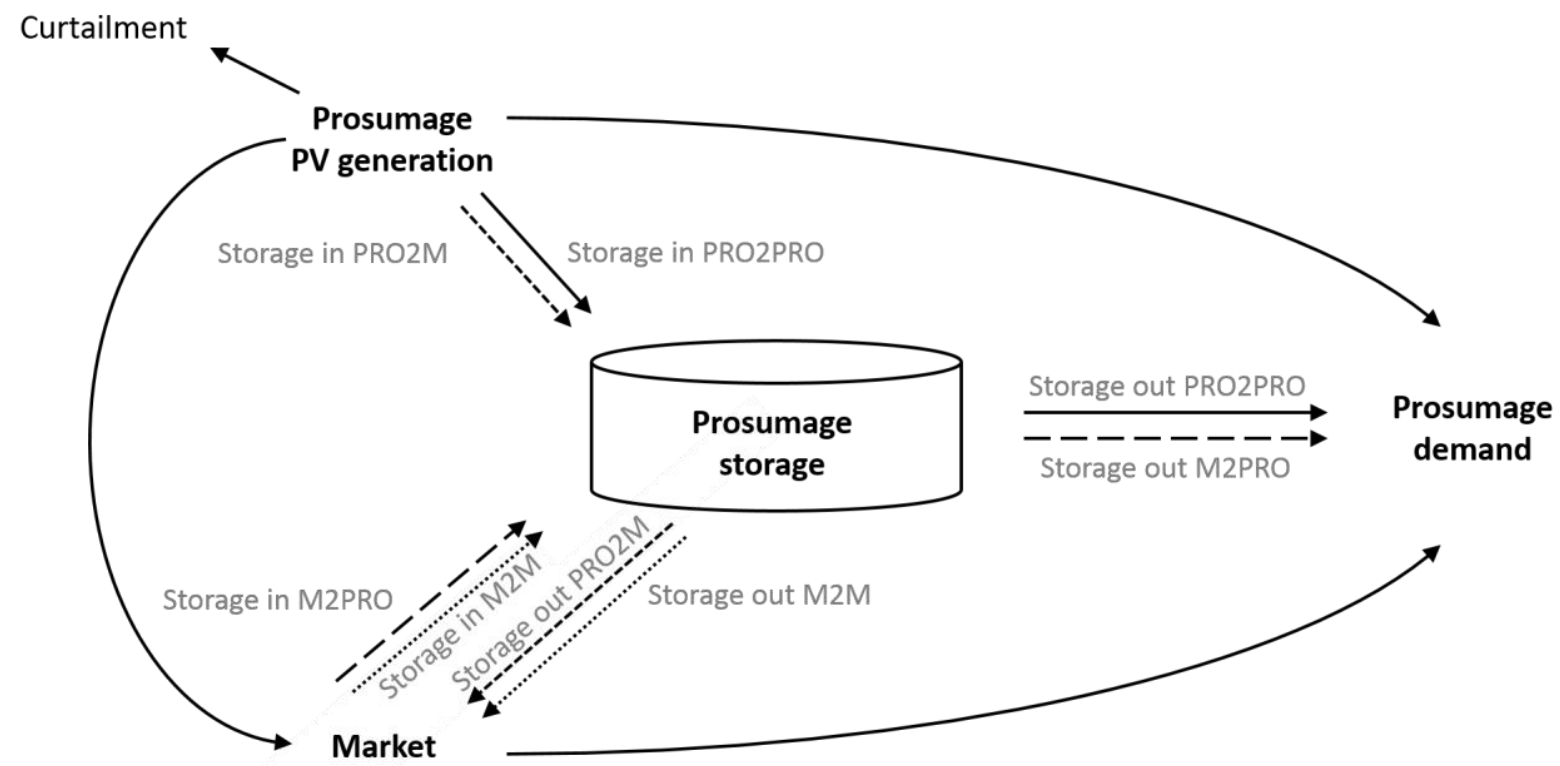

Figure 5: Schematic illustration of the prosumage segment in the augmented model. The links between the prosumage storage and the market are selectively disabled in the application to assess effects of different levels of prosumage market integration. Source: own illustration

The prosumage storage requires a detailed treatment. In the general model setup, it can be charged from both the market and self-generation, and can discharge to both the market and prosumagers (Figure 5). To track indirect self-generation through the storage, inflows and outflows are earmarked with both their origin and their destination. Specifically, the model features four separate virtual prosumage storage segments: prosumage-to-prosumage (PRO2PRO), prosumage-to-market (PRO2M), market-to-prosumage (M2PRO), and market-to-market (M2M). In each virtual segment, discharging must be enabled by previous charging in the same segment, corrected by efficiency losses. Overall, the sum of all four storage levels may not exceed total prosumage storage energy capacity. Likewise, the sum of inflows over all segments is restricted by hourly prosumage storage power capacity; and analogously for outflows.

Accordingly, our model setup only implicitly approximates prosumagers' incentives by means of a minimum self-generation constraint, which requires that at least a specified exogenous share of prosumager energy demand stems from direct PV self-consumption or from PV energy discharged from the prosumager battery. ${ }^{31}$ Minimum self-generation must hold over the entire year; hours with low self-generation can be offset by other hours. This allows abstracting from explicitly modeling retail prices and preserving the overall model setup with a system cost minimizing objective function. In

\footnotetext{
${ }^{31}$ Weniger et al. (2015) distinguish between a "self-consumption share" (share of direct own consumption and storage loading in overall PV generation) and an "autarky level" (share of direct own consumption and storage discharging in overall consumption). The latter resembles the self-generation share in our model analysis, also called "prosumage share" with a corresponding "prosumage restriction".
} 
contrast to the UK-based analysis provided by Green and Staffell (forthcoming), we assume the prosumage segment to face wholesale prices both with respect to PV feed-in ${ }^{32}$ and grid consumption.

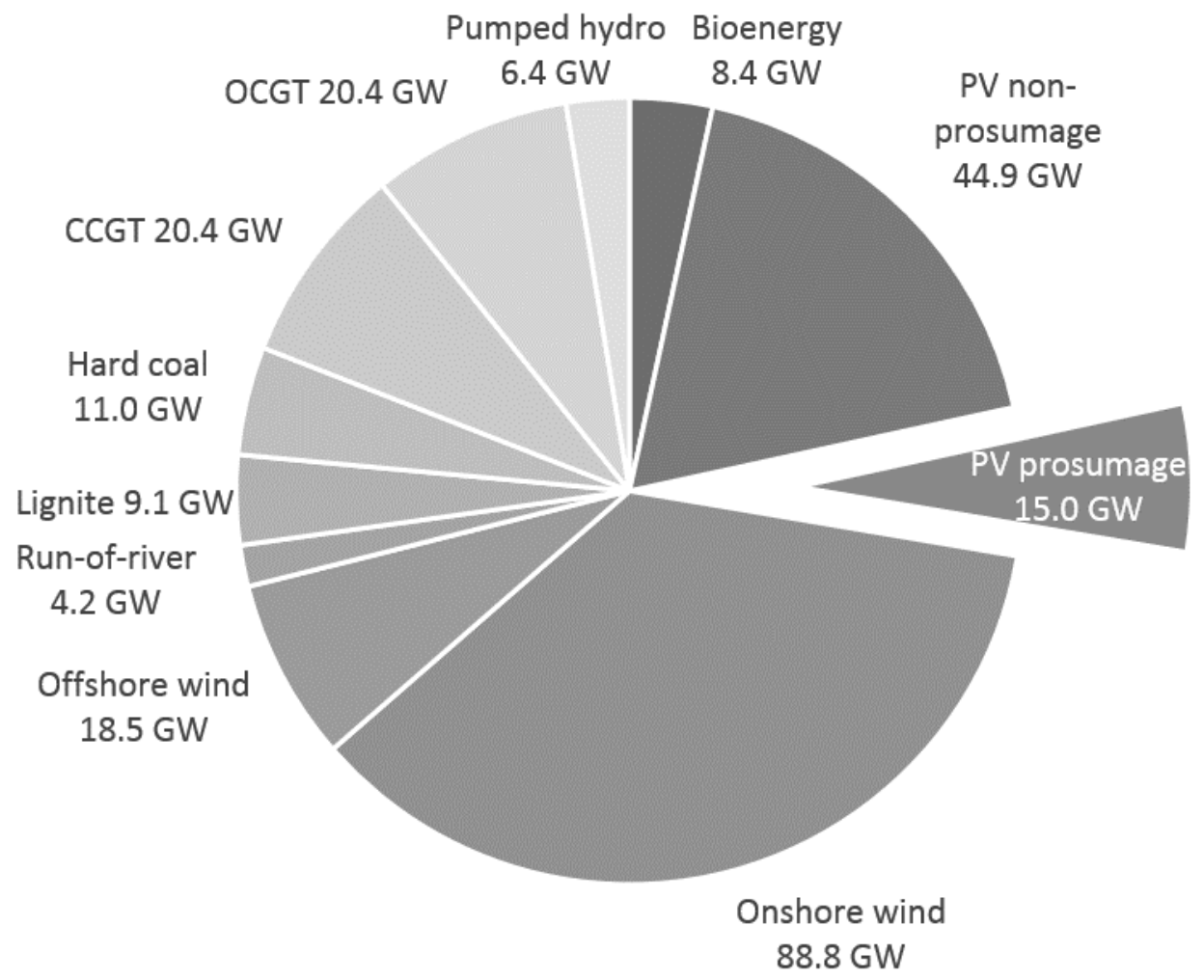

Figure 6: Installed capacity in German 2035 scenario. Source: scenario B1 2035 in BNetzA (2014), own assumption on prosumage 33

\subsection{Input data and scenarios}

We employ a brownfield version of DIETER. Conventional and renewable capacities are fixed and enter the model as data as projected in the scenario framework of the German Grid Development Plan (Netzentwicklungsplan, NEP) for the year 2035 (BNetzA 2014); ${ }^{34}$ see Figure 6. This portfolio corresponds to a yearly renewables share of about $66 \%$ in total electricity consumption. In the prosumage segment, we allow for lithium-ion battery storage investments. With respect to market (central) storage, investments in both lithium-ion batteries and pumped hydro storage are possible.

\footnotetext{
32 In this respect, our model follows the "market value approach" mentioned in European Commission (2015). We implicitly also reflect article 21 of the proposal for a revised European renewable directive, according to which i) renewable self-consumption should be possible "without being subject to disproportionate procedures and charges that are not cost-reflective" and ii) grid feed-in should be remunerated such that it "reflects the market value of the electricity fed in" (European Commission 2016).

${ }^{33}$ BNetzA (2014). Szenariorahmen 2025. Genehmigung. Bundesnetzagentur [German federal regulatory authority]. Bonn, 19.12.2014.

${ }^{34}$ All input parameters are provided on DIETER's homepage www.diw.de/dieter.
} 
Specific investment costs for the year 2035 are derived from Pape et al. (2014) with 58 Euro/kW and 263 Euro/kWh for lithium-ion batteries ${ }^{35}$, and 1,100 Euro/kW and 10 Euro/kWh for pumped hydro storage. We take the existing capacity of $6.4 \mathrm{GW}$ and $44,800 \mathrm{GWh}$ as a minimum requirement for the central pumped hydro storage. Thus, DIETER decides on the optimal hourly dispatch of all technologies, and investments into storage. ${ }^{36}$

We assume the same load and PV profiles for prosumagers as for overall load and PV generation, and exogenously attribute $25 \%$ of the overall solar PV peak capacity to prosumage (15 GW). The prosumage demand share is calibrated such that total annual prosumagers' load (12.7 TWh) equals 95\% of their respective potential PV generation. Assuming a yearly electricity demand of $5000 \mathrm{kWh}$ in prosumage households, this would correspond to about 2.6 million decentralized prosumage systems with a PV installation of $5.9 \mathrm{kWp}$ each.

We analyze four prosumage strategies, and a baseline case without prosumage. Specifically, we deactivate selective links between prosumage storage and the market as illustrated in Figure 5.

- Case (i), pure prosumage, de-activates all interactions of prosumage storage with the market. Thus, it can only be used to defer consumption of self-generated PV electricity to later periods, ${ }^{37}$

- Case (ii), grid consumption smoothing, activates only prosumage storage loading from the market. Thus, the storage can smooth prosumagers' electricity sourcing over both own PV and the market;

- Case (iii), PV profiling, activates only prosumager discharging to the market. Thus, prosumagers can profile their available PV grid feed-in, that is feed in PV energy from storage when it is most system-friendly (i.e. market prices are highest);

- Case (iv), full interaction, imposes no restrictions on the links between prosumage storage and the market. Thus, the storage can be used for consumption smoothing, PV profiling, and, additionally, market arbitrage.

Importantly, all four cases impose system-friendly prosumage behavior: as prosumagers do not have a separate objective function, overall cost minimization dispatches prosumage PV and storage installations in a system-optimal way while respecting the minimum self-generation requirement. This behavior can be rationalized straightforward within a prosumage segment being controlled by

\footnotetext{
${ }^{35}$ We accordingly assume substantial future cost decreases. For comparison, median system costs of lithium batteries installed in Germany in 2015 were somewhat below 2,000 Euro/kWh (RWTH 2016).

${ }^{36}$ For the sake of simplicity, we disable several model features, including DSM, reserves, and electric vehicles. Likewise, there is no explicit spatial dimension, that is, no representation of an electricity grid as well as no interactions with neighboring countries.

${ }^{37}$ This approach is common in many analyses. For example, see Moshövel et al. (2015).
} 
aggregators that aim at efficiency within the overall system. As such, system efficiency losses from additional prosumage restrictions can be assumed to be at a lower bound.

\subsection{Results}

In the baseline case, which features no prosumage segment, no additional storage is built. All intertemporal flexibility requirements can be efficiently met by the $6.4 \mathrm{GW}$ pumped storage capacity within the market segment that enters the model as data. We then solve each of the four cases for minimum self-generation levels between 40 and $70 \%$ of prosumagers' load, in $5 \%$ increments. Results are largely mirrored against baseline results to infer a quantitative assessment.

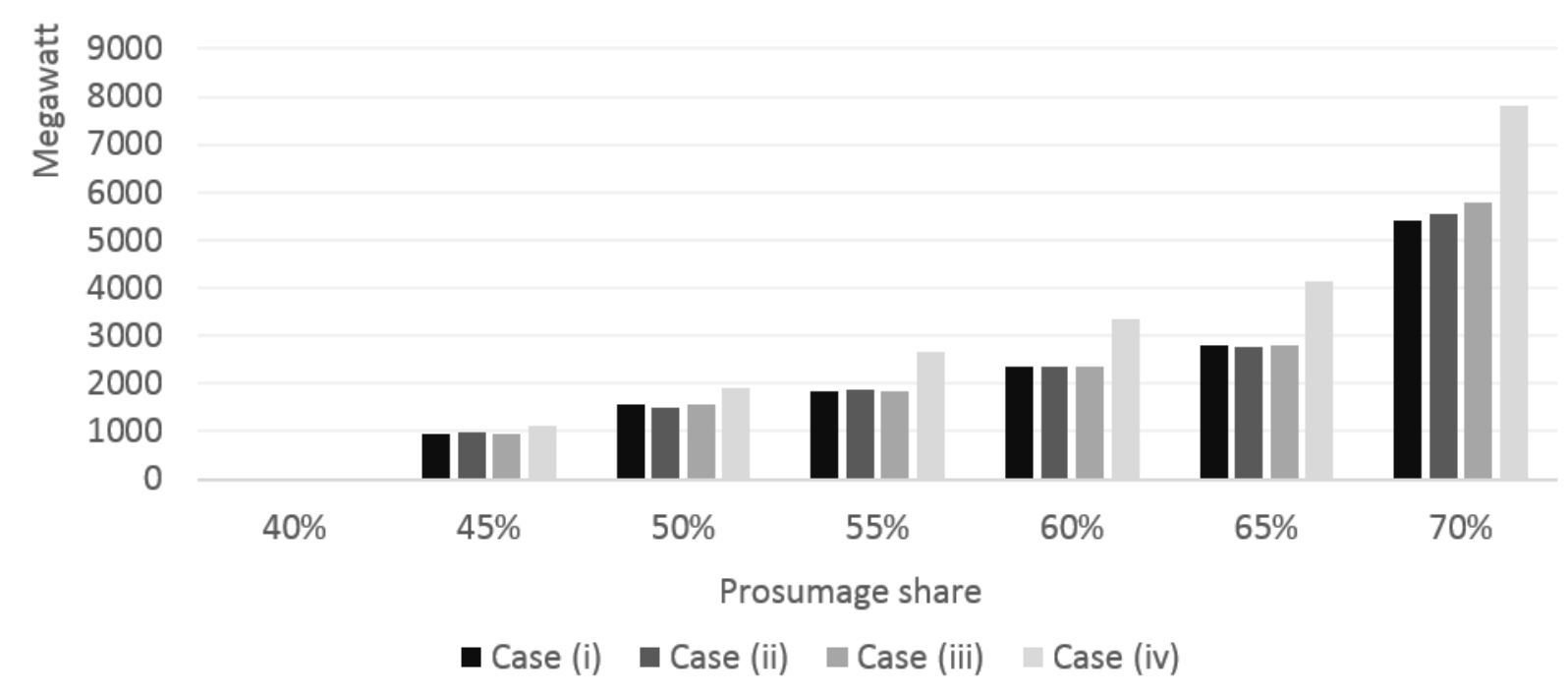

Figure 7: Storage deployment compared to the baseline. Increasing self-generation requirements trigger greater prosumage storage deployment. Source: own calculations

\subsubsection{Storage deployment}

Additional storage within the prosumage segment is built beginning from a minimum self-generation share of $45 \%$. Storage investments increase moderately until $65 \%$ minimum self-generation and grow strongly beyond (Figure 7). While differences across Cases (i)-(iii) are marginal, storage capacities are substantially greater in Case (iv), in which complete interaction of prosumager storage with the market is possible. For instance, under Case (iv) and 55\% minimum self-generation, about 2,800 MW battery power capacity, and nearly 6,700 MWh energy capacity, is built. With about 2.5 million prosumagers, thus, each prosumager, on average, complements its $5.9 \mathrm{kWp}$ PV module with a $1.1 \mathrm{~kW} / 2.6 \mathrm{kWh}$ battery storage. ${ }^{38}$

\footnotetext{
${ }^{38}$ Our results roughly correspond to the values mentioned in the review by Luthander et al. (2015), according to which a battery capacity of around 0.5-1.0 kWh per kW PV peak power is often applied.
} 


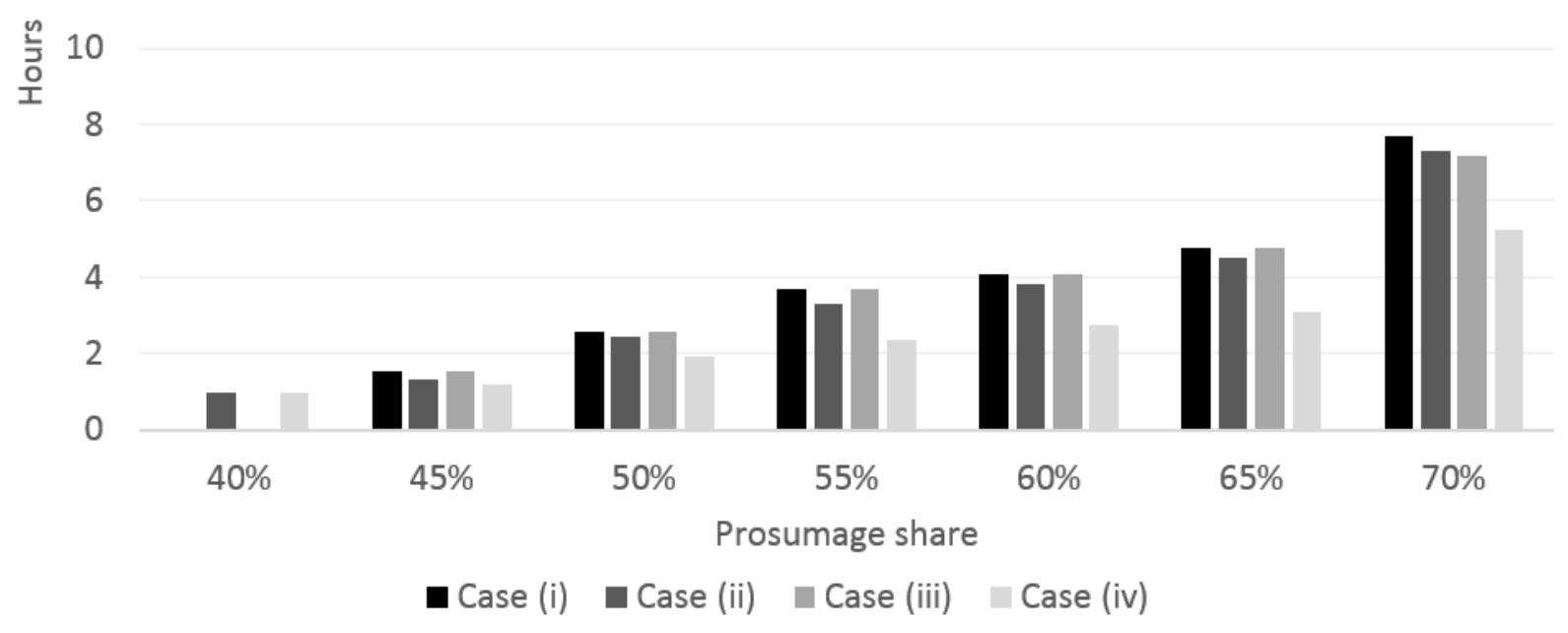

Figure 8: E/P ratios of prosumage storage. Increasing $\mathrm{E} / \mathrm{P}$ ratios shows that tighter self-generation restrictions require longerterm storage. Source: own calculations

Likewise, the energy-to-power ratio, or E/P ratio, which describes the storage layout with respect to the length of storage periods, rises with tighter self-generation restrictions; from below two hours for $45 \%$ to between five and eight hours for $70 \%$ (Figure 8 ). As prosumagers must fulfill ever stricter requirements, the storage is tailored to balance self-generation over longer periods. Across cases, E/P ratios are consistently lower in Case (iv), driven by higher storage power, which enters the E/P ratio in the denominator. As prosumage storages can fully interact with the market, they are more valuable to the overall system and, thus, deployed in higher amounts. At the same time, the energy capacity, which enters the E/P ratio in the numerator, is constant across cases because it is dimensioned only according to self-generation requirements, which are the same across all cases.

As our brownfield already setting features $6.4 \mathrm{GW}$ of pumped hydro storage, there is already substantial intertemporal flexibility in the market. In a sensitivity, we reduce the initial pumped hydro capacity to zero. In this setting, around $2 \mathrm{GW}$ of central storage capacity are built in the case without prosumage. Contrasting the central and prosumage storage capacities under tightening selfgeneration requirements sheds light on inefficiently redundant infrastructures (Figure 9). While prosumage storage capacities steadily rise, they offset only a minor part of the central market storage. Only in Case (iv), in which prosumage storage is also available for additional market interactions, the offset effect is substantial: in the $70 \%$ case, central storage is completely substituted. 


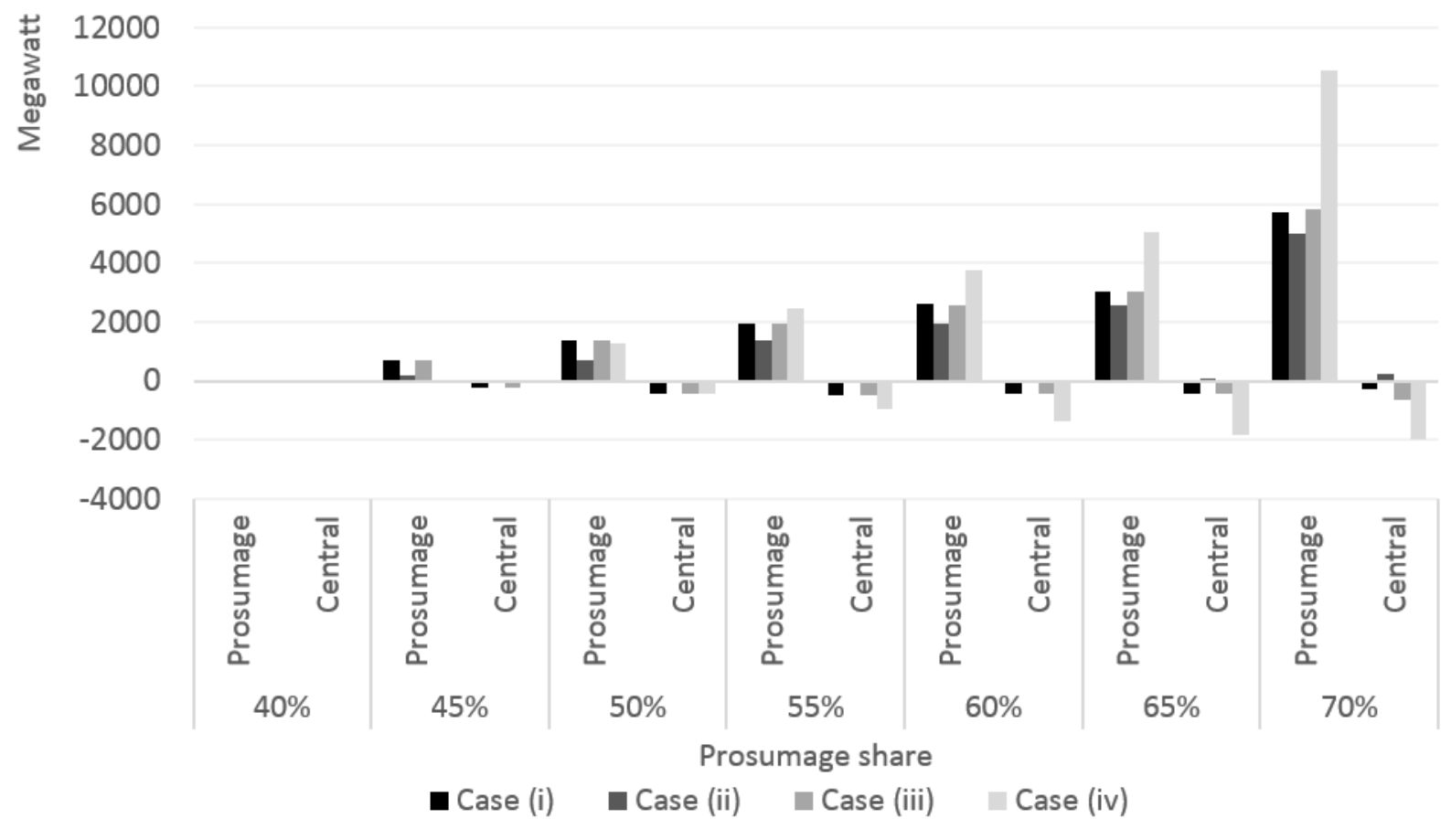

Figure 9: Deployment of prosumage storage and central storage in a sensitivity compared to a case without prosumage. Prosumage storage only partly substitutes central storage. Source: own calculations

\subsubsection{Storage patterns}

The analysis of dispatch pattern gives an indication of optimal prosumager behavior. Figure 10 displays two typical days in spring for Case (iv) with $55 \%$ self-consumption, in which the prosumage storage can fully interact with the market. ${ }^{39}$

PV generation follows a typical diurnal pattern. If PV supply exceeds demand, the excess energy is first sent to the market and afterwards used to fill the prosumage storage. In that way, the market is served preferentially in hours of high demand, and storage energy capacity can be dimensioned lower if the storage period is shorter. On market interactions of the prosumage storage, two findings stand out: first, the PRO2PRO storage pattern indicates that the storage energy capacity is determined by selfconsumption needs. The virtually identical storage energy capacities across cases - in particular, in the case without market interaction of prosumagers' batteries - underline this finding. Second, in night hours in which it is not required to serve self-consumption, the prosumage storage is filled with cheap market electricity, irrespective whether to serve the market or prosumers themselves. On the other hand, the prosumage storage does not serve to shift prosumagers' market exports to later hours. Such profiling is not optimal because high market values, in this example, coincide with PV availability.

\footnotetext{
${ }^{39}$ Note that generation and demand in should be interpreted as flows, and storage levels as stocks. The storage pattern also shows that grid-relieving reduction of peak PV feed-in is not part of the model's constraint set. Further, effects vary substantially between seasons, depending on load and insolation, the seasonal distribution of which may vary in other countries.
} 
Therefore, while full market interaction does not help to facilitate self-generation requirements directly, opening up the prosumage storage to the market bears an efficiency potential.

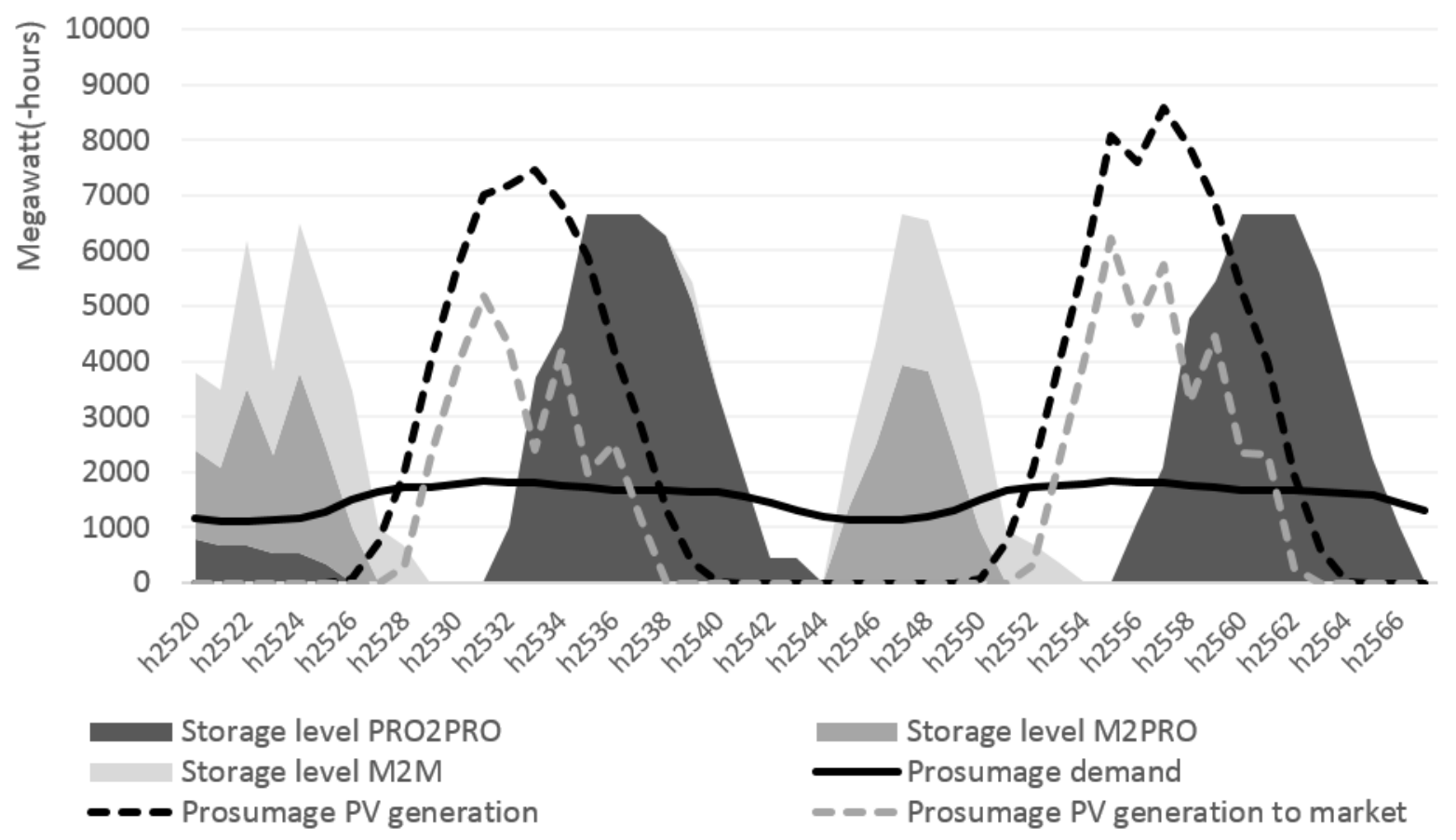

Figure 10: Demand, PV generation, and utilization pattern of prosumage storage by purpose over two days for Case (iv) with $55 \%$ self-consumption. Excess flexibility from prosumage storage is used for both smoothing grid consumption and market arbitrage. Source: own calculations

\subsubsection{Costs}

Self-generation requirements put additional restrictions on the model and, thus, lead to higher overall system costs. Whether the potential benefits of prosumage, which we discussed qualitatively, outweigh these costs cannot be assessed here. Figure 11 shows average additional cost per additional MWh self-generation compared to the baseline. While the cost increase is roughly linear up to $65 \%$ self-generation, additional costs grow strongly beyond. For instance, in Case (i) with a 55\% restriction, each excess MWh of self-generation over the baseline incurs system costs of about 33 Euro. Case (iv), i.e. full prosumage storage interaction, entails the lowest increases. Likewise, Case (ii), in which the prosumage storage can defer market consumption to cheap hours, yields lower cost increases than the other two cases. The absolute annual cost increase amounts to about 103-135 million Euro for 55\% self-generation, and $877-1,028$ million Euro for $70 \%$. This equals $0.1-0.2 \%$ and $2.5-2.9 \%$ of totals system costs, which range between 35 and 36 billion Euro in the respective cases. 


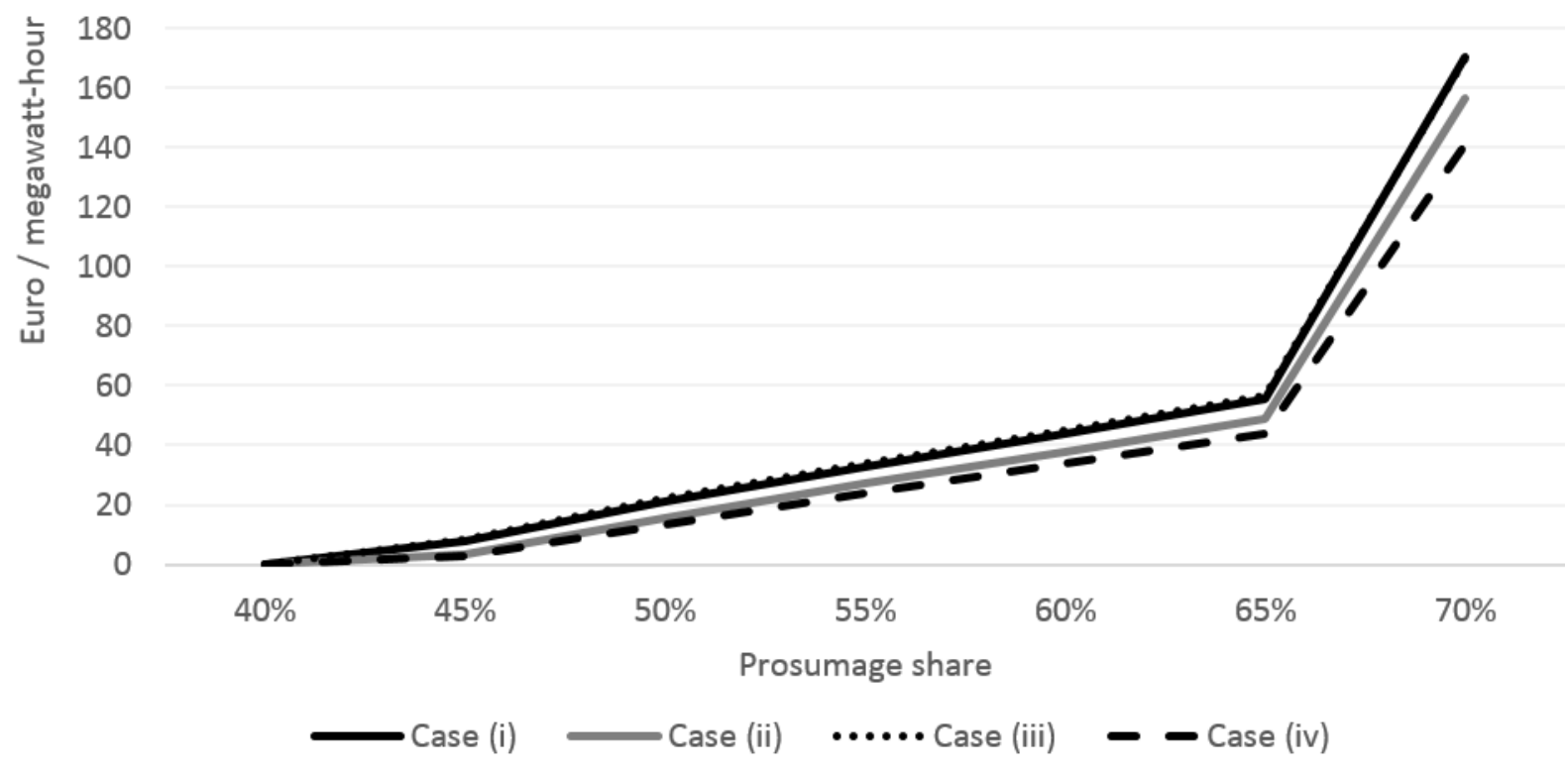

Figure 11: Additional costs compared to baseline. Costs over-proportionally increase with self-generation requirements. Source: own calculations

When tightening prosumage restrictions, two potentially opposing forces influence total costs: additional prosumage storage investments and an altered dispatch pattern. To disentangle the two channels, we subtract the additional storage investment costs from the cost delta to the baseline. Figure 12 indicates a U-shaped pattern: up to $65 \%$ self-generation, the additional flexibility from larger prosumage storage allows for a moderately more efficient dispatch. However, if the restriction gets too tight, the dispatch advantage is over-compensated by the costly need of fulfilling ever higher selfconsumption levels. Only in Case (iv), there is always a cost advantage as prosumage storage, beyond accommodating self-generation requirements, can provide additional flexibility to the market.

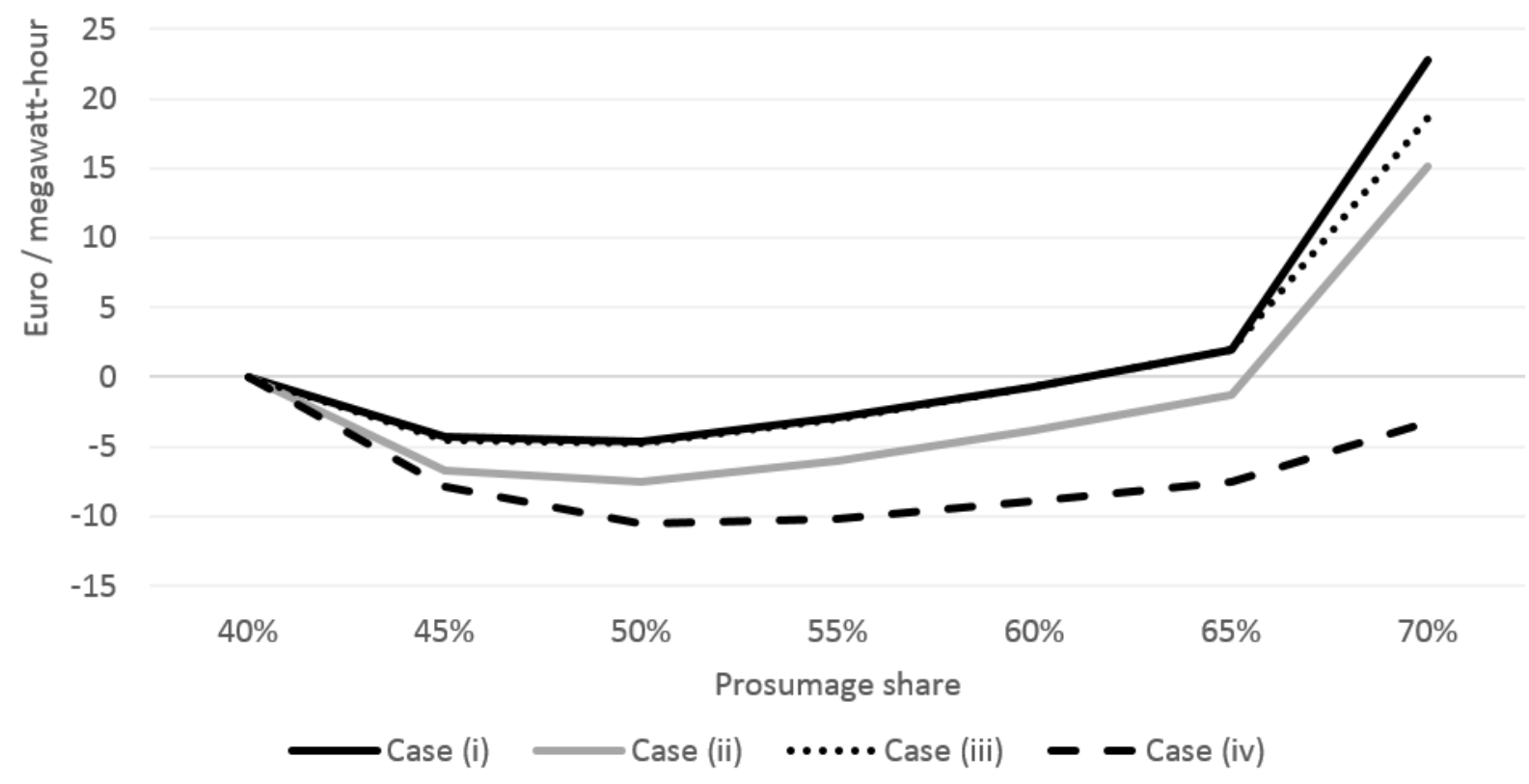

Figure 12: Additional costs compared to baseline without storage investments. Flexibility from the prosumage storage enables a more efficient dispatch. Source: own calculations 
This dispatch effect also materializes when comparing the absolute cost difference between Case (i) and Cases (ii) - (iv) in which some form of market interaction is allowed for prosumage storage. Figure 13 shows that opening up prosumage storage flexibility to the market can yield absolute cost savings up to 151 million Euro per year compared to the case in which prosumagers use their storage only to smooth their PV self-consumption.

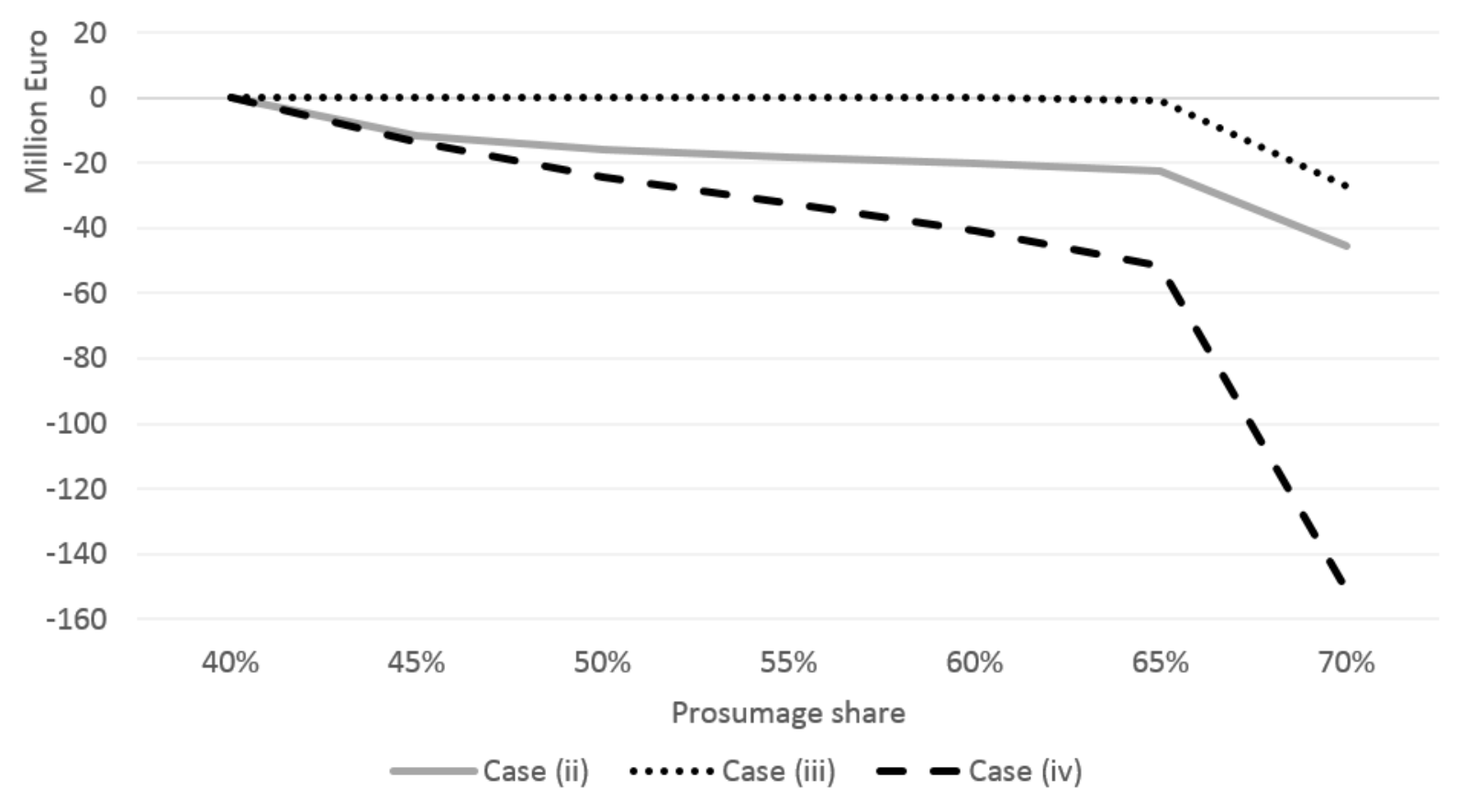

Figure 13 Cost differences compared to Case (i). Opening up prosumage storage to the market can lower overall system costs. Source: own calculations

\subsubsection{Market values}

Prosumager behavior, potentially facilitated by aggregators in the real world and approximated by additional restrictions in our optimal system dispatch model, is driven by market values and opportunity costs. Prosumagers have an incentive to achieve high market values for exports to the market, and low market values for imports, and to prevent unfavorable market values, respectively. The hourly system price is given by the marginal on the system energy balance. Figure 14 shows the average market values for prosumagers' storage and market transactions in Case (iv).

The difference between the black lines visualizes the strategy for using storage for self-consumption. Prosumagers charge when the market value is low, and release energy for themselves when the market value is high. When increasing self-generation restrictions, less favorable hours must be used and the market values converge. A similar pattern, though less pronounced, prevails for pure market arbitrage, as indicated by the solid gray lines. For tighter self-generation restriction, prosumagers can draw less energy from the market. As the storage becomes larger at the same time, the average market value of prosumagers' market consumption accordingly decreases. 


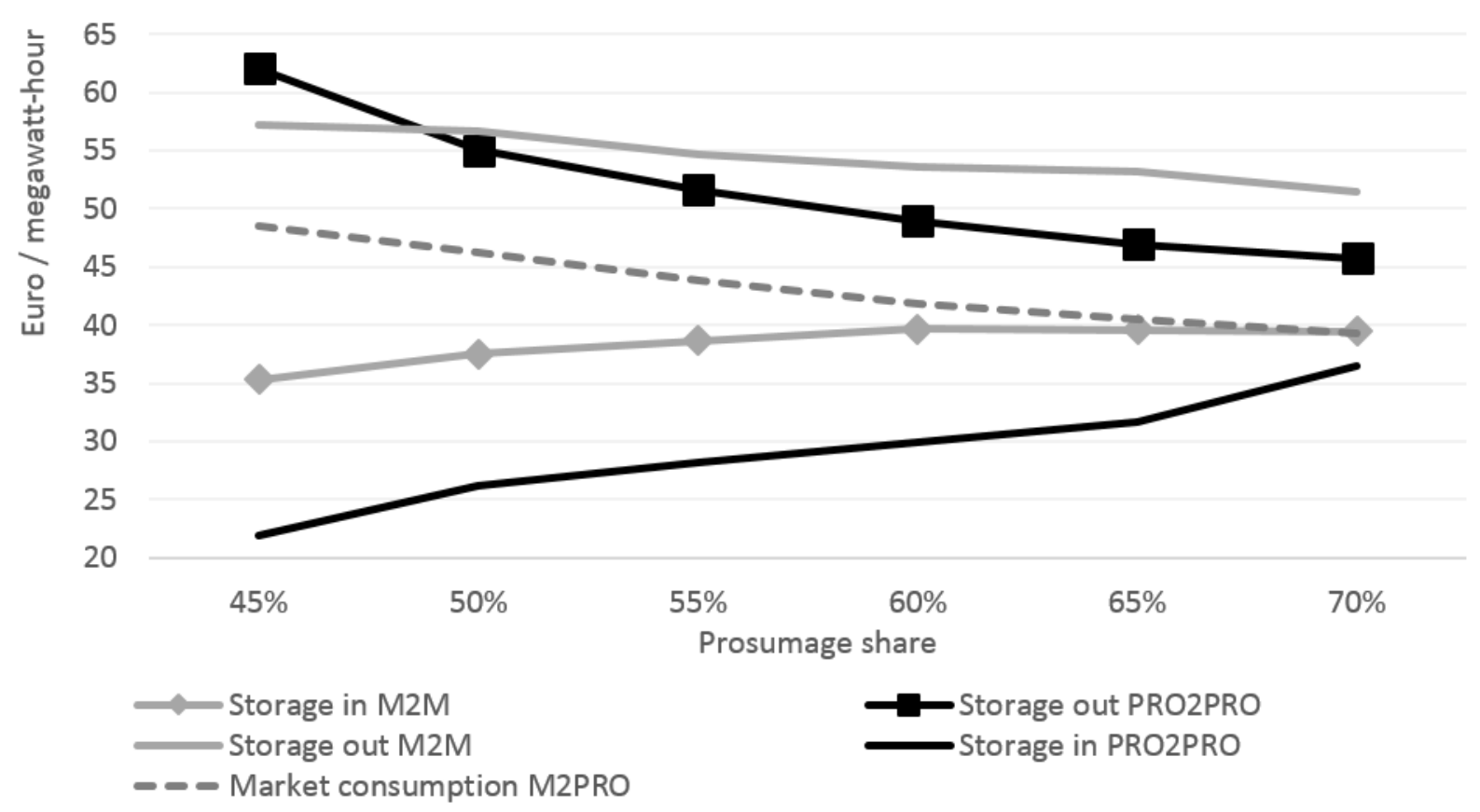

Figure 14: Market values. Prosumage storage is preferentially charged in times of low market values, and discharged under high market values. Source: own calculations

\subsection{Discussion of model limitations}

The model application serves as a quantitative illustration of prosumage system effects. As numerical findings depend on a large number of assumptions, numbers should not be taken at face value, but rather indicate a snapshot of system efficiency losses. Several open points remain: first, direct incentives for engaging in prosumage are not considered, such as a maximization of self-consumption or minimization of electricity costs. It should, again, be noted that - aside from the self-generation restriction - the prosumage segment behaves optimally from a system perspective. Alternatively, prosumage could also be modeled in a more myopic way, leading to storage operation as depicted on the left-hand side of Figure 1. Results should thus be interpreted rather as a lower bound for potential system efficiency losses.

Second, profiles of prosumage load and PV feed-in are the same as for the entire system. More realistic prosumer load and PV patterns could be expected to be less smooth (cf. Quoilin et al. 2016, Weniger et al. 2015). Depending on the type of consumer, load at night-time may often be lower than assumed in our analysis, while load at day-time may tend to fluctuate more. The correlation of supply and demand could be higher or lower compared to the stylized assumptions made here. Whether and to which extent self-generation restrictions were accordingly relieved or aggravated is not unanimous and is left to future research.

Third, an hourly model resolution does not take effects of intra-hourly variability into account, which may become important if specific load patterns of individual consumers are considered (cf. Luthander 
et al. 2015). Likewise, short-term system services, such as balancing reserves, are not analyzed. From both a system and a prosumer perspective, the absence of other flexibility options, for instance demand-side management or sector coupling, may lead to an over-restriction of the model. For example, additional power-to-heat applications could lead to substantially higher self-generation shares without additional battery storage requirements. Finally, the exogenous power plant park, which follows an established 2035 scenario for Germany, is potentially oversized and may, thus, provide too much flexibility to the model. The quantitative impacts of these simplifications could be explored in follow-up studies.

Importantly, the system simulation carried out here only determines additional system costs of prosumage because an otherwise optimized electricity system is subject to increasingly tight additional restrictions. An underlying assumption is that the central optimization is actually possible, that is, the centralized benchmark could actually be attained. What is more, efficiency losses would have to be contrasted to the positive aspects of prosumage discussed above. Yet quantifying these is beyond the scope of this paper and must be answered in further and complementary research.

\section{Summary and conclusions}

A discussion of arguments in favor of and against PV self-generation combined with distributed storage shows that several benefits have been attributed to this concept. While not all of these may be considered entirely convincing from an economic point of view, several arguments such as respective consumer preferences, a desire to actively participate in the energy transformation, and better public acceptance appear to be plausible, though challenging to quantify, and partly specific to particular perspectives. There is also range of drawbacks, such as efficiency losses when compared to (hypothetical) system optimization, and distributional impacts. How to weigh these pros and cons is beyond the scope of our analysis and, eventually, requires political decisions. Additional quantitative evidence on many of these impacts would in any case be desirable.

Our overview of prosumage developments in Germany shows that a range of indirect and direct support mechanisms already incentivizes prosumage to some degree. Yet it appears likely that batterysupported PV self-generation will gain additional momentum by the mid of the 2020s when large PV capacities drop out of the German support scheme. Our model-based illustration of possible system

effects of prosumage, calibrated to a German 2035 scenario, shows that growing self-generation shares increasingly require battery storage with ever larger E/P ratios. These prosumage storage installations go along with a notable substitution of other storage facilities only in case they are - while still serving self-generation requirements - fully available for additional market interactions. In this case, prosumage-related system cost increases are also minimal. Actually enabling such market 
interactions of prosumage batteries will likely require appropriate communication infrastructure, respective aggregators, and an appropriate regulatory framework.

We conclude that policy makers should not unnecessarily restrict the development of prosumage in order to realize its potentially beneficial effects in the context of the low-carbon energy transformation. At the same time, system and distributional aspects must be considered, and potentially detrimental technical or political path dependencies should be avoided. In particular, it appears to be beneficial to ensure system-oriented design and operation of prosumage installations, and to make their flexibility potential available for the power market to the largest extent possible. This would require a regulatory framework which gives prosumagers both rights and obligations (cf. CEER 2016, Pérez-Arriaga and Jenkins forthcoming). In general, prosumagers, or respective aggregators, should face the right (volatile) price signals in order to operate their installations in a system-oriented and flexible way. This could potentially be achieved by mandating, for example, smart metering in respective incentive schemes. More capacity-oriented grid charges would also work into this direction. Yet this notion contrasts with one of the selling points of PV storage systems, according to which their owners enjoy the benefit of being hedged from all price risks in the long run.

At the same time, consumers who can or do not want to switch to prosumage should not be unduly disadvantaged. The regulatory framework would have to find a balance between incentivizing prosumage just enough that its potentially beneficial effects can materialize, and only so much that distributive distortions between prosumers and non-prosumers are minimized, while promoting system-oriented design and operation of prosumage installations. Respective regulatory reforms are likely to be highly country-specific and remain subject for future research. 


\section{Appendix: Prosumage in the DIETER model}

Equation (1) distributes prosumagers' generation of renewable technology res in hour $h$, given as the product of the hourly availability factor of a variable renewable technology, $\phi_{h}^{\text {res }}$, and the installed capacity, $n_{\text {res }}^{\text {res,pro }}$, within the prosumer segment. Variables are denoted by capital letters, and parameters by lower-case letters throughout. Available generation is curtailed, $C U_{\text {res }, h}^{\text {pro }}$, fed to the market, $G_{r e s, h}^{\text {pro } 2 m}$, consumed directly, $G_{r e s, h}^{\text {proppro }}$, or stored, either earmarked being later discharged to self-consumption, $S T O_{\text {sto,res, } h}^{\text {in,pro }}$, or later discharged to the market, $S T O_{\text {sto,res, } h}^{\text {in } h \text { pro }}$.

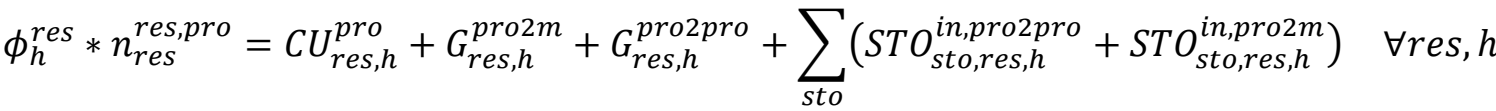

The prosumage energy balance (2) prescribes that hourly prosumager demand $\phi^{\text {pro,load }} * d_{h}$ is satisfied from direct self-generation, consumption from the market $G_{h}^{m 2 p r o}$ or storage outflow, either earmarked as stemming from self-generation, $S T O_{\text {sto,h }}^{\text {outpro2pro }}$, or the market, $S T O_{\text {sto, } h}^{\text {out }}$ 2pro .

$\phi^{\text {pro,load }} * d_{h}=\sum_{\text {res }} G_{r e s, h}^{\text {pro2pro }}+G_{h}^{\text {m2pro }}+\sum_{\text {sto }}\left(S T O_{\text {sto }, h}^{\text {out,pro2pro }}+S T O_{\text {sto }, h}^{\text {out }, \text { m2pro }}\right) \quad \forall h$

The prosumage restriction (3) imposes a minimum self-generation share $\phi^{\text {pro,self }}$ of prosumager demand, fulfilled through direct self-consumption or from stored and previously self-generated electricity.

$\sum_{\text {res, },} G_{r e s, h}^{\text {pro2pro }}+\sum_{\text {sto,h }} S T O_{\text {sto, } h}^{\text {out,pro2pro }} \geq \phi^{\text {pro,self }} * \sum_{h} \phi^{\text {pro,load }} * d_{h}$

For each type of storage, that is pro2pro (prosumage-to-prosumage), pro $2 \mathrm{~m}, \mathrm{~m} 2 \mathrm{pro}$, and $\mathrm{m} 2 \mathrm{~m}$, a virtual storage segment is subject to a law of motion: the storage level an hour, $S T O_{\text {sto,h }}^{l, p r o 2 p r o}$, equals the storage level in the previous hour altered by contemporaneous inflows and outflows, corrected by efficiency losses related to both storage loading and discharging.

$$
\begin{aligned}
S T O_{\text {sto }, h}^{l, p r o 2 p r o}= & S T O_{\text {sto }, h-1}^{l, p r o 2 p r o}+\frac{1+\eta_{\text {sto }}^{\text {sto }}}{2} * \sum_{\text {res }} S T O_{\text {sto }, \text { res }, h}^{\text {in,pro } h \text { pro }}-\frac{2}{1+\eta_{\text {sto }}^{\text {sto }}} \\
& * S T O_{\text {sto }, h}^{\text {out } \text { pro } 2 \text { pro }} \quad \forall \text { sto }, h
\end{aligned}
$$

All virtual storage levels together constitute the overall prosumage storage level

$$
S T O_{\text {sto }, h}^{l, p r o}=S T O_{\text {sto,h }}^{l, p r o 2 p r o}+S T O_{\text {sto }, h}^{l, p r o 2 m}+S T O_{\text {sto }, h}^{l, m 2 p r o}+S T O_{\text {sto }, h}^{l, m 2 m} \quad \forall s t o, h
$$

which is restricted by available storage energy capacity

$$
S T O_{\text {sto,h }}^{l, p r o} \leq N_{\text {sto }}^{\text {sto,E,pro }} \quad \forall \text { sto, } h
$$

Likewise, storage power capacities take effect for the entirety of all four hourly storage outflows 


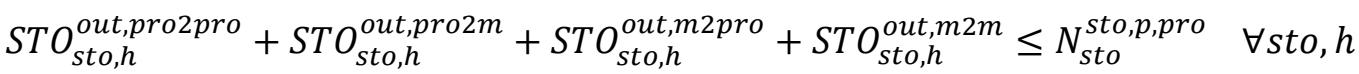

and analogously for storage inflows.

\section{References}

Anda, M. and J. Temmen (2014). "Smart metering for residential energy efficiency: The use of community based social marketing for behavioural change and smart grid introduction." Renewable Energy 67: 119-127. http://dx.doi.org/10.1016/j.renene.2013.11.020

Bardt, H., E. Chrischilles, C. Growitsch, S. Hagspiel and L. Schaupp (2014). „Eigenerzeugung und Selbstverbrauch von Strom - Stand, Potentiale und Trends". Zeitschrift für Energiewirtschaft 38: 8399. http://dx.doi.org/10.1007/s12398-014-0133-0

Borenstein, S. (2015). "The private net benefits of residential solar PV: the role of electricity tariffs, tax incentives and rebates." NBER Working Paper 21342. www.nber.org/papers/w21342

Castillo-Cagigal, M., E. Caamaño-Martín, E. Matallanas, D. Masa-Bote, A. Gutiérrez, F. MonasterioHuelin and J. Jiménez-Leube (2011). "PV self-consumption optimization with storage and Active DSM for the residential sector." Solar Energy 85(9): 2338-2348.

http://dx.doi.org/10.1016/i.solener.2011.06.028

Chiaroni, D., V. Chiesa and F. Frattini (2014). "Chapter 14 - Renewable Energy Generation: Incentives Matter: A Comparison Between Italy and Other European Countries." In: Global Sustainable Communities Handbook, edited by Woodrow W. Clark, Boston, 2014, 347-367.

http://dx.doi.org/10.1016/B978-0-12-397914-8.00014-X

CEER (2016). CEER Position Paper on Renewable Energy Self-Generation. Council of European Energy Regulators, September 2016.

http://www.ceer.eu/portal/page/portal/EER HOME/EER PUBLICATIONS/CEER PAPERS/Electricity/2 016/C16-SDE-55-03 Renewable\%2520Self-Consumption PP.pdf

Deutsch, M. and P. Graichen (2015). What if... there were a nationwide rollout of PV battery systems? A preliminary assessment. Background Paper, Agora Energiewende. October 2015. https://www.agora-energiewende.de/fileadmin/Projekte/2015/PV-SpeicherRollout/Agora Speicherdurchbruch 2015-10-08 web EN.pdf

Egerer, J. and W.-P. Schill (2014). "Power System Transformation toward Renewables: Investment Scenarios for Germany." Economics of Energy \& Environmental Policy 3(2): 29-43.

http://dx.doi.org/10.5547/2160-5890.3.2.jege

Eid, C., J.R. Guillén, P.F. Marín and R. Hakvoort (2014). "The economic effect of electricity netmetering with solar PV: Consequences for network cost recovery, cross subsidies and policy objectives." Energy Policy 75: 244-254. http://dx.doi.org/10.1016/i.enpol.2014.09.011

European Commission (2015): Commission Staff Working Document: Best practices on Renewable Energy Self-consumption. SWD(2015) 141 final. Brussels, 15.7.2015. http://eur-lex.europa.eu/legalcontent/EN/TXT/PDF/?uri=CELEX:52015SC0141 
European Commission (2016): Proposal for a Directive of the European Parliament and of the Council on the promotion of the use of energy from renewable sources (recast). COM(2016) 767 final.

Brussels, 30.11.2016.

http://ec.europa.eu/energy/sites/ener/files/documents/1 en act part1 v7 1.pdf

Fürsch, M., S. Hagspiel, C. Jägemann, S. Nagl, D. Lindenberger and E. Tröster (2013). „The role of grid extensions in a cost-efficient transformation of the European electricity system until 2050." Applied Energy 104: 642-652. http://dx.doi.org/10.1016/j.apenergy.2012.11.050

Gährs, S., K Mehler, M. Bost and B. Hirschl (2015). „Acceptance of Ancillary Services and Willingness to Invest in PV-storage-systems." Energy Procedia 73: 29 - 36.

http://dx.doi.org/10.1016/j.egypro.2015.07.554

Green R. and I. Staffell (forthcoming): "Prosumage" in the electricity market." Economics of Energy \& Environmental Policy.

Haller, M., S. Ludig and N. Bauer (2012). „Decarbonization scenarios for the EU and MENA power system: Considering spatial distribution and short term dynamics of renewable generation." Energy Policy 47: 282-290. http://dx.doi.org/10.1016/i.enpol.2012.04.069

Hoppmann, J., J. Volland, T.S. Schmidt and V.H. Hoffmann (2014). "The economic viability of battery storage for residential solar photovoltaic systems - A review and a simulation model." Renewable and Sustainable Energy Reviews 39: 1101-1118. http://dx.doi.org/10.1016/j.rser.2014.07.068

IEA (2014). Residential prosumers - drivers and policy options (RE-PROSUMERS). IEA-RETD.

September 2014 (Revised version of June 2014). http://iea-retd.org/wp-

content/uploads/2014/09/RE-PROSUMERS IEA-RETD 2014.pdf

Keirstead, J. (2007). "Behavioural responses to photovoltaic systems in the UK domestic sector." Energy Policy 35(8): 4128-4141. http://dx.doi.org/10.1016/j.enpol.2007.02.019

Luthander, R., J. Widén, D. Nilsson and J. Palm (2015). "Photovoltaic self-consumption in buildings: A review." Applied Energy 142: 80-94. http://dx.doi.org/10.1016/j.apenergy.2014.12.028

MacDonald, A.E., C.T.M. Clack, A. Alexander, A. Dunbar, J. Wilczak and Y. Xie (2015). "Future costcompetitive electricity systems and their impact on US $\mathrm{CO}_{2}$ emissions." Nature Climate Change 6: 526-53. http://dx.doi.org/10.1038/nclimate2921

MacGill, I. and R. Smith (forthcoming). Consumers or prosumers, customers or competitors? Australian perspectives on possible energy users of the future. Economics of Energy \& Environmental Policy.

May, N. and K. Neuhoff (2016). "Eigenversorgung mit Solarstrom" - ein Treiber der Energiewende? DIW Roundup 89.

https://www.diw.de/documents/publikationen/73/diw 01.c.523542.de/diw roundup 89 de.pdf

Mayr, D., E. Schmid, H. Trollip, M. Zeyringer and J. Schmidt. "The impact of residential photovoltaic power on electricity sales revenues in Cape Town, South Africa." Utilities Policy 36 (2015): 10-23. http://dx.doi.org/10.1016/i.jup.2015.08.001

Michaels, L. and Y. Parag (2016). "Motivations and barriers to integrating 'prosuming' services into the future decentralized electricity grid: Findings from Israel." Energy Research \& Social Science 21: 70 - 83. http://dx.doi.org/10.1016/j.erss.2016.06.023 
Moshövel, J., K.-P. Kairies, D. Magnor, M. Leuthold, M. Bost, S. Gährs, E. Szczechowicz, M. Cramer and D.U. Sauer (2015). "Analysis of the maximal possible grid relief from PV-peak-power impacts by using storage systems for increased self-consumption." Applied Energy 137: 567-575.

http://dx.doi.org/10.1016/j.apenergy.2014.07.021

Motlagh, O., P. Paevere, T.S. Hong and G. Grozev (2015). "Analysis of household electricity consumption behaviours: Impact of domestic electricity generation." Applied Mathematics and Computation 270: 165-178. http://dx.doi.org/10.1016/j.amc.2015.08.029

Neuhoff, K., J. Diekmann, F. Kunz, S. Rüster, W.-P. Schill and S. Schwenen (2016). “A coordinated strategic reserve to safeguard the European energy transition." Utilities Policy 41: 252-263.

http://dx.doi.org/10.1016/i.jup.2016.02.002

NREL (2013). Regulatory Considerations Associated with the Expanded Adoption of Distributed Solar. Technical Report NREL/TP-6A20-60613. November 2013. www.nrel.gov/docs/fy14osti/60613.pdf

Oberst, C.A., and R. Madlener (2015). "Prosumer Preferences Regarding the Adoption of MicroGeneration Technologies: Empirical Evidence for German Homeowners." FCN Working Paper 22/2014.

https://www.fcn.eonerc.rwth-aachen.de/global/show document.asp?id=aaaaaaaaaaogwnx

Ohlhorst, D. (2015). "Germany's energy transition policy between national targets and decentralized responsibilities." Journal of Integrative Environmental Sciences 12(4): 303-322.

http://dx.doi.org/10.1080/1943815X.2015.1125373

Pape, C. et al. (2014). Roadmap Speicher. Endbericht. Fraunhofer IWES, IAEW, Stiftung Umweltenergierecht. November 2014. http://publica.fraunhofer.de/eprints/urn nbn de 0011-n3161279.pdf

Parag, Y. and Sovacool, B.K. (2016): "Electricity market design for the prosumer era." Nature Energy 1, article number 16032. http://dx.doi.org/10.1038/nenergy.2016.32

Pérez-Arriaga, I.J. and J.D. Jenkins (forthcoming). "A regulatory framework for an evolving electricity sector: highlights of the MIT Utility of the Future Study." Economics of Energy \& Environmental Policy.

Picciariello, A., C. Vergara, J. Reneses, P. Frías and L. Söder (2015). “Electricity distribution tariffs and distributed generation: Quantifying cross-subsidies from consumers to prosumers." Utilities Policy 37: 23-33. http://dx.doi.org/10.1016/i.jup.2015.09.007

Prognos (2016). Eigenversorgung aus Solaranlagen. Das Potenzial für Photovoltaik-Speicher-Systeme in Ein- und Zweifamilienhäusern, Landwirtschaft sowie im Lebensmittelhandel. Analyse im Auftrag von Agora Energiewende. Berlin, October 2016.

Quoilin, S., K. Kavvadias, A. Mercier, I. Pappone and A. Zucker (2016). "Quantifying self-consumption linked to solar home battery systems: Statistical analysis and economic assessment." Applied Energy 182: 58-67. http://dx.doi.org/10.1016/j.apenergy.2016.08.077

RMI (2014). The Economics of Grid Defection: When and Where Distributed Solar Generation Plus Storage Competes with Traditional Utility Service. Rocky Mountain Institute, February 2014. http://www.rmi.org/electricity grid defection\#economics of grid defection

RMI (2015). The Economics of Load Defection: How Grid-Connected Solar-Plus-Battery Systems Will Compete with Traditional Electric Service, Why it Matters, and Possible Paths Forward. Rocky 
Mountain Institute, April 2015. http://www.rmi.org/cms/Download.aspx?id=11580\&file=201505 RMI-TheEconomicsOfLoadDefection-FullReport.pdf

Römer, B., P. Reichhart, J. Kranz and A. Picot (2012). "The role of smart metering and decentralized electricity storage for smart grids: The importance of positive externalities." Energy Policy 50: 486495. http://dx.doi.org/10.1016/i.enpol.2012.07.047

Schill, W.-P., M. Niemeyer, A. Zerrahn and J. Diekmann (2016). "Bereitstellung von Regelleistung durch Elektrofahrzeuge: Modellrechnungen für Deutschland im Jahr 2035." Zeitschrift für Energiewirtschaft 40: 73-87. http://dx.doi.org/10.1007/s12398-016-0174-7

Schill, W.-P. and A. Zerrahn (forthcoming). "Long-run power storage requirements for high shares of renewables: results and sensitivities." Renewable and Sustainable Energy Reviews.

SPE (2015). Renewable Self-Consumption Cheap and Clean Power at your Doorstep. Policy Paper. SolarPower Europe, June 2015.

http://www.solarpowereurope.org/fileadmin/user upload/documents/Policy Papers/Selfconsumption final1507.pdf

SPE (2016). Ahead of the Pack. Solar, the new Gateway to the decentralised Energy System. SolarPower Europe, May 2016.

Tractebel and Ecofys (2015). Identifying Energy Efficiency improvements and saving potential in energy networks, including analysis of the value of demand response, in support of the implementation of article 15 of the energy efficiency directive (2012/27/EU). Final report. December 2015.

https://ec.europa.eu/energy/sites/ener/files/documents/GRIDEE 4NT 36417400001 TOTALDOC $\% 20-\% 2018-1-2016 . p d f$

Toffler, A. (1980). The Third Wave. Bantam Books.

Weniger, J., J. Bergner, T. Tjaden and V. Quaschning (2015). Dezentrale Solarstromspeicher für die Energiewende. Studie. Hochschule für Technik und Wirtschaft HTW Berlin. June 2015. http://pvspeicher.htw-berlin.de/wp-content/uploads/2015/05/HTW-Berlin-Solarspeicherstudie.pdf Zerrahn, A. and W.-P. Schill (forthcoming). „Long-run power storage requirements for high shares of renewables: review and a new model." Renewable and Sustainable Energy Reviews. 